\title{
Batch Soil Adsorption and Column Transport Studies of 2,4- dinitroanisole (DNAN) in Soils
}

\author{
Jennifer D. Arthur ${ }^{1,}$ Noah W. Mark ${ }^{1}$, Susan Taylor ${ }^{2}$, Jiri Šimůnek ${ }^{5}$, Mark L. Brusseau ${ }^{1,3}$, and \\ Katerina M. Dontsova $a^{1,4^{*}}$
}

\footnotetext{
${ }^{1}$ Soil, Water and Environmental Science Department, University of Arizona

${ }^{2}$ U.S. Army Engineer Research and Development Center

${ }^{3}$ Hydrology and Water Resources Department, University of Arizona

${ }^{4}$ Biosphere 2, University of Arizona

${ }^{5}$ University of California, Department of Environmental Sciences
}

*Corresponding author

429 Shantz Bldg

Tucson, AZ, 85721 


\section{ABSTRACT}

The explosive 2,4,6-trinitrotoluene (TNT) is currently a main ingredient in munitions; however the compound has failed to meet the new sensitivity requirements. The replacement compound being tested is 2,4-dinitroanisole (DNAN). DNAN is less sensitive to shock, high temperatures, and has good detonation characteristics. However, DNAN is more soluble than TNT, which can influence transport and fate behavior and thus bioavailability and human exposure potential. The objective of this study was to investigate the environmental fate and transport of DNAN in soil, with specific focus on sorption processes. Batch and column experiments were conducted using soils collected from military installations located across the United States. The soils were characterized for $\mathrm{pH}$, electrical conductivity, specific surface area, cation exchange capacity, and organic carbon content. In the batch rate studies, change in DNAN concentration with time was evaluated using the first order equation, while adsorption isotherms were fitted using linear and Freundlich equations. Solution mass-loss rate coefficients ranged between $0.0002 \mathrm{~h}^{-1}$ and 0.0068 $\mathrm{h}^{-1}$. DNAN was strongly adsorbed by soils with linear adsorption coefficients ranging between 0.6 and $6.3 \mathrm{~L} \mathrm{~kg}^{-1}$, and Freundlich coefficients between 1.3 and $34 \mathrm{mg}^{1-\mathrm{n}} \mathrm{L}^{\mathrm{n}} \mathrm{kg}^{-1}$. Both linear and Freundlich adsorption coefficients were positively correlated with the amount of organic carbon and cation exchange capacity of the soil, indicating that similar to TNT, organic matter and clay minerals may influence adsorption of DNAN. The results of the miscible-displacement column experiments confirmed the impact of sorption on retardation of DNAN during transport. It was also shown that under flow conditions DNAN transforms readily with formation of amino transformation products, 2-amino-4-nitroanisole and 4-amino-2-nitroanisole. The magnitudes of retardation and transformation observed in this study result in significant attenuation potential for 
DNAN, which would be anticipated to contribute to a reduced risk for contamination of ground water from soil residues.

Keywords: 2, 4-dinitroanisole (DNAN), 2-amino-4-nitroanisole (2-ANAN), 4-amino-2-

nitroanisole (4-ANAN), soil adsorption, organic carbon (OC), cation exchange capacity (CEC) 


\section{INTRODUCTION}

The United States military uses the high explosive compound 2, 4, 6-trinitrotoluene (TNT) as one of the main ingredients in munitions. TNT is sensitive to shock and temperature, presenting a significant danger for unintended detonation. The Department of Defense is transitioning to so-called insensitive munitions (IM) to increase soldier safety (Jurgensen, 2000). This effort has resulted in the replacement of TNT with 2,4-dinitroanisole (DNAN) a compound that meets sensitivity requirements (Boddu et al., 2009). DNAN is a nitrated aromatic compound similar to TNT in composition and structure (Fig. s1). It is less sensitive to stimuli than TNT and, as its melting point is similar to that of TNT, it can replace TNT in melt cast munitions (Davies and Provatas, 2006).

Limited information is available regarding DNAN's environmental fate and potential impact on humans and the environment. Both DNAN and its transformation products exhibit microbial toxicity (with amino products being less toxic than DNAN) (Liang et al., 2013); as well as toxicity to higher organisms (Dodard et al., 2013). However, DNAN toxicity is comparable to or less than that of TNT (Dodard et al., 2013; Stanley et al., 2015). Toxicity of the amino derivatives of DNAN, 2-ANAN (2-amino-4-nitroanisole) and 4-ANAN (4-amino-2nitroanisole) has not been established. They have shown to have both lower (Liang et al., 2013) and higher (Olivares et al., 2016) microbial toxicity than DNAN.

Incomplete or low-order detonations that scatter explosives on training ranges is one of the main ways explosives enter the environment. IMs containing DNAN are more likely to result in incomplete detonations than traditional explosives (Walsh et al., 2013). DNAN is also more soluble than TNT in water, $276.2 \mathrm{mg} \mathrm{L}^{-1}$ at $25^{\circ} \mathrm{C}$ (Boddu et al., 2008) compared to 103.1 for 
TNT (Ro et al., 1996), and laboratory studies show that DNAN is readily dissolved from IM formulations when exposed to water (Taylor et al., 2013; Taylor et al., 2015).

Like TNT, DNAN can transform in the environment via reduction of nitro groups to amino groups and form a series of products, such as 2-amino-4-nitroanisole (2-ANAN), 4amino-2-nitroanisole (4-ANAN), and 2,4-diaminoanisole (DAAN) (Olivares et al., 2013; Hawari et al., 2015). While transformation pathways have been determined, transformation rates in soils have not been measured. Two major routes of transformation have been shown under anaerobic and aerobic conditions. Perreault et al. (2011) reported the aerobic biotransformation of DNAN in artificially contaminated soil microcosms. In their study, DNAN formed 2-ANAN indicating regioselective reduction of the ortho-nitro group. However, others have found that anaerobic conditions lead to formation of observed DNAN transformation products. Platten et al. (2010) used anaerobic fluidized-bed bioreactors to investigate the biological pathways of transformation for DNAN. They found that DNAN transforms into diaminoanisole (DAAN) and when exposed to air, it formed azobond polymers. Additionally, Olivares et al. (2016) investigated the aerobic and anaerobic DNAN (bio)transformation in soils. Their results showed little evidence that DNAN transforms under aerobic conditions and DNAN's removal was attributed to adsorption to the organic carbon in the soil. However, under anaerobic conditions DNAN was (bio)transformed to 2-ANAN and 10 additional transformation products including 4-ANAN which is an isomer of 2-ANAN.

DNAN's adsorption behavior is less well known. DNAN reactions with lignin may remove DNAN from contaminated water (Saad et al., 2012) by H-bonding. The effectiveness of lignin as a DNAN sorbent suggests that soil organic matter may adsorb DNAN. It was also observed that cellulose can weakly adsorb DNAN through H-bonding (Shukla and Poda, 2016). 
Mesocosm studies, using an insensitive formulation containing DNAN, in the presence of plants reported no DNAN in drainage and in plant biomass, indicating soil retention, adsorption and/or transformation (Braida et al., 2011).

Hawari et al. (2015) investigated the environmental fate of DNAN and its reduced products, 2-ANAN, 4-ANAN, and DAAN. These researchers conducted batch adsorption studies for these compounds with two sterilized soil materials. Their findings showed that DNAN was reversibly adsorbed by the soils, while 2-ANAN and 4-ANAN sorbed both reversibly and irreversibly, and DAAN sorbed irreversibly. This behavior is similar to that of TNT, which becomes easily reduced in the environment (nitro to amino groups) with resulting compounds adsorbing both reversibly (Dontsova et al., 2006) and irreversibly (Thorn and Kennedy, 2002; Thorn et al., 2002) to the organic matter in the soils. Reversible adsorption of TNT can happen through several mechanisms, depending on polarity of organic matter, including hydrophobic interactions mediating association with particulate organic carbon and polar interactions with dissolved organic carbon (Eriksson and Skyllberg, 2001).

Since environmental behaviors of DNAN and TNT are similar, we can expect that DNAN would interact with the same soil components as TNT. In general, organic carbon (OC) is often the best predictor of adsorption behavior of organic compounds, particularly non-ionic ones like DNAN (e.g., Site, 2001). In addition, TNT is adsorbed by phyllosilicate clays (Haderlein et al., 1996; Dontsova et al., 2009) suggesting that they may also adsorb DNAN. This was confirmed by Linker et al. (2015). The sorption is influenced by the type of exchangeable cation, similar to other nitroaromatic compounds (Haderlein et al., 1996), with DNAN interacting directly with the cation. 
Given the paucity of information concerning the sorption and transport behavior of DNAN, the main objective of the present work is to: examine the fate of DNAN in soils; quantify the extent of DNAN reversible adsorption; quantify mass loss through other mechanisms related to the chemical and physical properties of the soils; and assess relationships between DNAN adsorption and soil properties. Batch and column experiments were conducted using soils collected from military installations located across the United States. The 11 soils were characterized for $\mathrm{pH}$, specific surface area (SSA), electrical conductivity (EC), OC content, and cation exchange capacity (CEC) to help understand the interactions between DNAN and soils.

\section{METHODS}

\section{Soil collection and characterization}

Surface soils (0-20 cm depth) were collected from uncontaminated sites on ten U.S. Army National Guard training ranges and one from the University of Illinois farm. Soil series names and classifications for all soils are listed in Table 1. The selected soils represent a range of climates and conditions on military ranges where live fire training occurs. These soils span several soil orders with different moisture regimes, including Entisols, Inceptisols, Mollisols, Aridisols, and Ultisols. Soils in the text are identified by location where they were collected except Plymouth, Catlin, and Sassafras, which are identified by series name. 
Table 1. Soils used to study interaction with DNAN. Soil names, classification according to US Taxonomy, and location where collected is listed.

\begin{tabular}{|c|c|c|}
\hline Soil name & Soil classification & Location \\
\hline Catlin & $\begin{array}{l}\text { Catlin silt loam, mixed, mesic, superactive } \\
\text { Oxyaquic Argiudoll }\end{array}$ & Urbana, IL \\
\hline Fort Harrison & $\begin{array}{l}\text { Musselshell sandy loam, carbonatic, frigid Aridic } \\
\text { Calciustepts }\end{array}$ & $\begin{array}{l}\text { Fort William Henry } \\
\text { Harrison, MT }\end{array}$ \\
\hline Arnold AFB & $\begin{array}{l}\text { Captina silt loam, siliceous, mesic, typic } \\
\text { Fragiudults }\end{array}$ & $\frac{\text { Arnold Air Force Base, }}{\mathrm{TN}}$ \\
\hline Plymouth & $\begin{array}{l}\text { Plymouth loamy sand, mesic, coated Typic } \\
\text { Quartzipsamment }\end{array}$ & $\begin{array}{l}\text { Massachusetts Military } \\
\text { Reservation, MA }\end{array}$ \\
\hline Camp Butner & $\begin{array}{l}\text { Helena sandy loam, mixed, semiactive, thermic } \\
\text { Aquic Hapludults }\end{array}$ & Camp Butner, NC \\
\hline $\begin{array}{l}\text { Limestone } \\
\text { Hills }\end{array}$ & $\begin{array}{l}\text { Musselshell sandy loam, carbonatic, frigid Aridic } \\
\text { Calciustepts }\end{array}$ & Limestone Hills, MT \\
\hline Sassafras & Sassafras loam, siliceous, mesic Typic Hapudult & $\begin{array}{l}\text { Aberdeen Proving } \\
\text { Ground, MD }\end{array}$ \\
\hline Camp Gruber & $\begin{array}{l}\text { Verdigris silt loam, mixed, superactive, thermic } \\
\text { Cumulic Hapludolls }\end{array}$ & Camp Gruber, OK \\
\hline $\begin{array}{l}\text { Camp } \\
\text { Guernsey }\end{array}$ & $\begin{array}{l}\text { Keeline-Turnercrest loam, mixed, superactive, } \\
\text { calcareous, mesic Ustic Torriorthents }\end{array}$ & Camp Guernsey, WY \\
\hline Florence MR & $\begin{array}{l}\text { Cherioni loam, mixed, superactive, hyperthermic, } \\
\text { shallow Typic Haplodurids }\end{array}$ & $\begin{array}{l}\text { Florence Military } \\
\text { Reservation, AZ }\end{array}$ \\
\hline Camp Swift & $\begin{array}{l}\text { Bergstrom sandy clay loam, mixed, superactive, } \\
\text { thermic Cumulic Haplustolls }\end{array}$ & Camp Swift, TX \\
\hline
\end{tabular}

Collected soils were air dried, sieved $(<2 \mathrm{~mm})$, and characterized before the experiments. Soil OC content was measured using a Shimadzu SSM-5000A Solid Sample Combustion Unit following pretreatment with $5 \%$ phosphoric acid $\left(\mathrm{H}_{3} \mathrm{PO}_{4}\right)$ to ensure a complete removal of inorganic carbon (U.S. Environmental Protection Agency, 2010). Cation exchange capacity was determined using the sodium acetate method (U. S. Environmental Protection Agency, 1986). A VWR SympHony SB70P Benchtop Digital $\mathrm{pH}$ and EC Meter was used to measure $\mathrm{pH}$ and EC in a 1:1 soil to solution mixture. Particle size was determined using a Beckman Coulter LS 13320 Laser Diffraction Particle Size Analyzer. A Beckman Coulter SA 3100 was used to measure SSA by $\mathrm{N}_{2}$ adsorption applying Brunauer-Emmett-Teller theory (Brunauer et al., 1938). The 
mineralogy of the clay fraction in the soils was analyzed by X-ray diffraction for the following samples: Mg-exchanged, Mg-exchanged glycerol solvated, $\mathrm{K}$-exchanged at 25,300 and $550^{\circ} \mathrm{C}$. DNAN stock solutions

DNAN was provided by Picatinny Arsenal. Stock solution of $10 \mathrm{mg} \mathrm{L}^{-1}$ DNAN was prepared by dissolving solid DNAN in deionized water on a magnetic stir plate for 24 hours. The stock solution was then diluted to a final concentration with $0.005 \mathrm{M} \mathrm{CaCl}_{2}$. All prepared solutions were wrapped in aluminum foil to prevent phototransformation and sealed with Parafilm. Samples and stock solutions were stored in a refrigerator at approximately $4^{\circ} \mathrm{C}$. Analytical methods

2,4-dinitroanisole samples were analyzed using a Dionex Ultimate 3000 high performance liquid chromatograph (HPLC) equipped with a diode array detector (ThermoFisher, MA). The running method was adapted from Olivares et al. (2013). The parameters used for analyzing DNAN samples were the following: a mobile phase ratio of 43:57 methanol and water; the Thermo Scientific Acclaim reversed phase column C-18 with 5- $\mu$ m particle size; and a flow rate of $1 \mathrm{~mL} \mathrm{~min}^{-1}$. The wavelengths used for detection and quantification were $300 \mathrm{~nm}$ for DNAN, $254 \mathrm{~nm}$ for 2-ANAN, 4-ANAN, and $210 \mathrm{~nm}$ for DAAN.

\section{Batch soil adsorption}

Batch adsorption methods were adapted from Roy et al. (1992). Preliminary studies were performed to determine soil solution ratios that would result in adsorption of 10 to $30 \%$ of added solute, a range shown to minimize error of determined adsorption coefficients (Roy et al., 1992; McDonald and Evangelou, 1997). A series of soil to solution ratios ranging from 1:4 to 1:60 were tested. Aliquot of $20 \mathrm{~mL}$ of $0.5 \mathrm{mg} \mathrm{L}^{-1}$ DNAN solution was added to each $30 \mathrm{~mL}$ 
borosilicate glass centrifuge tube containing varying amounts of soil, from 0.33 to $5 \mathrm{~g}$. Nonsterilized soil was used for all experiments except where specifically noted.

Blanks and samples containing soil were continuously agitated on a reciprocating shaker at $110 \mathrm{rpm}$ for $24 \pm 0.5$ hours at room temperature away from light. After agitation, the samples were centrifuged for 20 minutes at $4700 \mathrm{rpm}$ (4816 relative centrifugal force). A minimum of 3 $\mathrm{mL}$ of supernatant was filtered with a $0.45 \mu \mathrm{m}$ Millex-HV PVDF filter and placed in $4 \mathrm{~mL}$ amber vials. All samples were analyzed using high performance liquid chromatography as described above. The $\mathrm{pH}$ and EC of each sample was determined on an aliquot using a SympHony SB70P Benchtop Digital pH and EC Meter.

We used soil to solution ratios determined in the preliminary experiments (Table s1) for all subsequent tests. To determine the time needed to achieve equilibrium, samples were analyzed at eight time intervals: $1,4,8,24,48,72,96$, and 120 hours. The input concentration of DNAN used was $0.5 \mathrm{mg} \mathrm{L}^{-1}$ in a $0.005 \mathrm{M} \mathrm{CaCl}_{2}$ aqueous solution. Three replicates were prepared for each time interval, as well as blank samples without soil. After agitation for a set period of time, samples were centrifuged and filtered as described previously. The $\mathrm{pH}$ and $\mathrm{EC}$ were measured for each sample. Aliquots for each sample were collected and analyzed to determine the amount of DNAN remaining in solution, as well as presence of DNAN transformation products. The equilibrium time was defined as the minimum amount of time needed to establish a rate change of solute concentration equal or less than 5\% per 24 hour time interval (Roy et al., 1992). The mass-loss rate coefficients, $k$, were determined from the change in the solute concentrations over time for the time period commencing after adsorption equilibrium. To confirm that the removal of DNAN from solution at the determined equilibrium point represented reversible soil adsorption and was not influenced by other processes such as 
irreversible adsorption and transformation (microbial or abiotic), we repeated the experiments for Catlin silt loam and Sassafras loam soils using both unsterilized and sterilized samples and extracted soil samples to determine the amount of DNAN retained in the soil. The soils were sterilized by autoclaving for an hour at $120^{\circ} \mathrm{C}$, repeated three times over 3 days. Following the sorption equilibration period, the DNAN solution was removed for analysis. The soils were then extracted by adding $20 \mathrm{~mL}$ of acetonitrile to each vial. The samples were agitated on a reciprocating shaker for 24 hours, centrifuged and filtered. Both solution samples and acetonitrile extracts were analyzed using HPLC. The mass of DNAN recovered in soil and solution were used to calculate the DNAN mass balance.

Once the equilibration time was established, experiments were conducted to develop multipoint adsorption isotherms. Eight different input concentrations, 2.03, 4.06, 8.12, 16.2, 32.5, 65.0, and $130 \mathrm{ppm}$ (or 10.3, 20.5, 41.0, 81.8, 164.1, 328.3, and $656.6 \mu \mathrm{mol} \mathrm{L}^{-1}$ ) of DNAN in $0.005 \mathrm{M} \mathrm{CaCl}_{2}$, were used to construct the isotherms. Each sample was prepared in triplicate. The equilibration time used was 24 hours for all soils. As previously described the samples were agitated, centrifuged, filtered, and analyzed using HPLC. We plotted soil concentrations calculated based on DNAN removal from solution against the solution concentrations and fit them using both the linear and Freundlich adsorption equation. From the plots, we determined the linear adsorption coefficient, $K_{d}\left(\mathrm{~L} \mathrm{~kg}^{-1}\right), K_{f}$, the Freundlich adsorption coefficient $\left(\mathrm{mg}^{1-\mathrm{n}} \mathrm{L}^{\mathrm{n}}\right.$ $\mathrm{kg}^{-1}$ ) and $n$, an empirical parameter that indicates the affinity of the compound for the adsorbent. The regression analysis function in Microsoft Excel 2007 was used to determine adsorption parameters, confidence intervals for the estimate, $R^{2}$ and probabilities of parameters being significantly different from zero. The Freundlich equation was linearized to allow linear regression. In addition, the linearized Freundlich adsorption coefficient, $K_{d}{ }^{L}$ was defined as: 


$$
K_{d}^{L}=K_{f} * C^{n-1}
$$

$K_{d}{ }^{L}$ values depend on the solution concentration used for calculation. Concentrations used for this study ranged from $0.5 \mathrm{mg} \mathrm{L}^{-1}$ to $130 \mathrm{mg} \mathrm{L}^{-1}$. A $50 \mathrm{mg} \mathrm{L}^{-1}$ solution concentration was used to calculate $K_{d}{ }^{L}$. The linear and Freundlich adsorption coefficients were used to determine the retardation factors of DNAN in each soil. The retardation factor for linear adsorption was defined as:

$$
R=1+\rho_{b} K_{d} / \theta
$$

While retardation factor for the Freundlich adsorption coefficients was defined as:

$$
R_{f}=1+\frac{\rho_{b}}{\theta} n K_{f} C^{n-1}
$$

where $\rho_{b}$ is bulk density, $\theta$ is the volumetric water content, and $C$ is the concentration of DNAN. To calculate $R$ and $R_{f}$, the neural network prediction application in HYDRUS-1D was used to estimate the porosity (as approximation of volumetric water content) of each soil based on the textural class. The porosity was then used to calculate the bulk density. Two different concentrations of DNAN $\left(0.5\right.$ and $\left.50 \mathrm{mg} \mathrm{L}^{-1}\right)$ were assumed for $R_{f}$ calculations.

Adsorption parameters were compared between the soils to assess the effect of the soil type on adsorption. Soil properties such as OC content, $\mathrm{pH}$, clay content, and CEC were evaluated for their impact on the adsorption of DNAN and to help predict the environmental fate of the compound in soil.

\section{Transport Study}

To provide a conservative estimate of the potential for DNAN transport in soils, two of the soils that had low DNAN attenuation (adsorption and transformation) in batch studies, Camp Guernsey and Camp Swift, were selected for the column experiments. They were packed into Supelco (Belfonte, PA) glass columns with $7 \mathrm{~cm}$ length and $1.18 \mathrm{~cm}$ internal diameter and sealed 
with PTFE caps. Glass wool was placed at the bottom of the columns and on top of the soil profile to prevent soil movement. Approximately 11 to 12 grams of soil was packed homogenously resulting in the average $\rho_{b}$ of $1.54 \pm 0.02 \mathrm{~g} \mathrm{~cm}^{-3}$ for Camp Swift and $1.62 \pm 0.02$ $\mathrm{g} \mathrm{cm}^{-3}$ for Camp Guernsey soil. Column study experiments were conducted in duplicate.

The columns were saturated with $0.005 \mathrm{M} \mathrm{CaCl}_{2}$ for one hour from the bottom to avoid trapping air in the pores. After saturation, the column pore volume (PV) was determined as the volume of solution required to saturate the packed column, minus the dead volume associated with the column. The column pore volume for Camp Swift soil columns was $2.92 \pm 0.23 \mathrm{~mL}$ and for Camp Guernsey soil columns $2.88 \pm 0.07 \mathrm{~mL}$. A Gilson 305 piston pump (Middleton, WI), attached to the top of the column using stainless steel tubing, delivered a $0.5 \mathrm{mg} \mathrm{L}^{-1}\left(2.8 \mu \mathrm{mol} \mathrm{\textrm {L } ^ { - }}\right.$ ${ }^{1}$ ) DNAN solution with $0.005 \mathrm{M} \mathrm{CaBr}_{2}$ tracer at $\sim 0.015 \mathrm{~mL} \mathrm{~min}^{-1}$ flow rate, equivalent to a mean Darcy flux of $0.81 \mathrm{~cm} \mathrm{~h}^{-1}$. The effluent was collected in 4-mL amber glass vials using a custom fraction collector with 49-vial capacity built by Bricmanagement (Tucson, AZ). The average sample volume collected in each vial was $0.59 \pm 0.07 \mathrm{~mL}$. Volumetric flow rate was calculated by measuring the weight of the collected effluent. After the effluent reached steady-state concentrations the solution was switched back to the background solution $\left(0.005 \mathrm{M} \mathrm{CaCl}_{2}\right)$ to observe DNAN desorption from the soil. Flow interruption studies were also conducted to further investigate mass transfer behavior (Brusseau et al., 1989; Brusseau et al., 1997). Flow was interrupted for 24 hours to allow DNAN to equilibrate with the soil. During the flow interruption the column remained saturated.

DNAN and its transformation products were quantified using HPLC as described above. The conservative tracer, $\mathrm{CaBr}_{2}$, was analyzed using Ion Chromatography (Dionex ICS 5000 with 
diode array). The bromide breakthrough curves were analyzed to determine longitudinal dispersivity $(\lambda)$ and observe for preferential flow for each soil.

After the end of each experiment, the column was divided into thirds and weighed. Extractions were performed on each soil sample to determine the amount of DNAN and its transformation products remaining in the soil. A mixture of soil and acetonitrile in 1:2 ratio was agitated for 24 hours, centrifuged, filtered through $0.45 \mu \mathrm{m}$ Millex-HV PVDF filter (EMD Millipore Darmstadt, Germany), and analyzed using HPLC (U. S. Environmental Protection Agency, 1994).

Numerical Analysis

Numerical analysis of effluent concentrations for the column experiments was performed using temporal moment analysis (TMA) (e.g., Pang et al., 2003) and the HYDRUS-1D code (Šimůnek et al., 2008). TMA, a non-parametric statistical analysis tool used to characterize a time series of samples collected at a particular point, was used to determine solute transport parameters such as the $K_{d}$, retardation factor, $R, \lambda$, and mass balance ratio. The analysis does not rely on an underlying model of solute transport and thus, unlike HYDRUS-1D, is not based on solving the inverse problem. However, the disadvantage of this analysis is that it cannot predict solute concentration based on physical processes.

Experiments were also analyzed using HYDRUS-1D (Šimůnek et al., 2008) for simulating the one-dimensional movement of water, heat and multiple solutes in variably saturated porous media. Transport of the $\mathrm{Br}^{-}$tracer and reactive solutes (e.g., the parent compound DNAN and its daughter product 2-ANAN) was described using the advectiondispersion equation:

$$
\partial \theta C_{w} / \partial t+\rho_{b} \partial C_{s} / \partial t=(\partial / \partial z) *\left[\theta D\left(\partial C_{w} / \partial z\right)\right]-\partial q C_{w} / \partial z-\varphi
$$


where $C_{\mathrm{s}}$ is the sorbed concentration $\left[\mathrm{MM}^{-1}\right], \theta$ is the volumetric water content $\left[\mathrm{LL}^{-3}\right], \rho_{b}$ represents the bulk density of the porous medium $\left[\mathrm{ML}^{-3}\right], C_{\mathrm{w}}$ represents the solute concentration $\left[\mathrm{ML}^{-3}\right], \varphi$ is the sink/source term that accounts for zero, first order and other reactions $\left[\mathrm{ML}^{-3} \mathrm{~T}^{-}\right.$ $\left.{ }^{1}\right]$, and $q$ is the volumetric fluid flux density $\left[\mathrm{LT}^{-1}\right]$ evaluated by Darcy-Buckingham law. $D$ is the dispersion coefficient, which represents both hydrodynamic dispersion and molecular diffusion $\left[\mathrm{L}^{2} \mathrm{~T}^{-1}\right]$ :

$$
D=\lambda v+D^{*}
$$

where the term $\lambda$ is the longitudinal dispersivity $[\mathrm{L}], v$ is the average linear velocity $\left[\mathrm{LT}^{-1}\right]$ and $D^{*}$ represents the effective diffusion coefficient $\left[\mathrm{L}^{2} \mathrm{~T}^{-1}\right]$. In this model, $\varphi$ is equal to zero for the nonreactive $\mathrm{Br}^{-}$tracer. For the parent compound DNAN degradation is assumed to occur only in the liquid phase and the first-order degradation rate $\left[\mathrm{ML}^{-3} \mathrm{~T}^{-1}\right]$ is defined as:

$$
\varphi=k \theta C_{w}
$$

where $k$ represents the mass-loss rate coefficient due to transformation and/or irreversible adsorption $\left(\mathrm{T}^{-1}\right), C_{w}$ and $\theta$ were as defined previously. Finally, for the daughter product 2ANAN, the first-order reaction rate $\left[\mathrm{ML}^{-3} \mathrm{~T}^{-1}\right]$ is defined as:

$$
\varphi=k \theta C_{w}-k_{p} \theta C_{w p}
$$

where the first term on the right side represents degradation of a daughter product (i.e., 2ANAN), while the second term represents a production of a daughter product by degradation of a parent compound (i.e., DNAN). In eq. $7, k_{p}$ and $C_{w p}$ represent the degradation rate $\left[\mathrm{T}^{-1}\right]$ and solute concentration $\left[\mathrm{ML}^{-3}\right]$ of a parent compound. The inverse mode was used to analyze breakthrough curves to obtain estimated best-fit values for selected parameters. Numerical analysis of the experimental data was performed by first simulating the conservative tracer breakthrough curves to characterize water flow and estimate $\lambda$. TMA calculated values for $\lambda$ 
were used as the initial inputs for HYDRUS-1D simulations of $\mathrm{Br}^{-}$breakthrough curves. It was observed that the HYDRUS-1D estimates of $\lambda$ determined from $\mathrm{Br}^{-}$breakthrough better characterized dispersivity in DNAN simulations than TMA estimates for DNAN (Table 4). Batch adsorption results for $K_{d}\left(\mathrm{~L} \mathrm{~kg}^{-1}\right)$ and $k\left(\mathrm{~h}^{-1}\right)$ were used as initial estimates for DNAN transport parameters in HYDRUS-1D. Mass balance calculations were also performed for DNAN and its transformation products (Table 5).

\section{RESULTS}

\section{Soil characterization}

Results of chemical and physical analyses of the eleven soils selected for this study are presented in Table 2. Soils are listed in order of decreasing OC content. The soils differed significantly in all measured parameters, including OC content $(0.34-5.28 \%), \mathrm{pH}(4.23-8.21)$, clay content $(4.1-32.3 \%), \operatorname{SSA}\left(1.7-38.3 \mathrm{~m}^{2} \mathrm{~g}^{-1}\right)$, and mineralogy.

\section{DNAN batch adsorption studies}

Preliminary studies showed that DNAN was strongly adsorbed by the soils, and for many soils the lowest soil to solution ratio, 1:60, was needed to achieve target solute removal from solution (Table s1).

\section{$\underline{\text { Rate studies }}$}

Rate studies provide the equilibration time for adsorption and the mass-loss rate coefficients of DNAN after adsorption equilibrium is attained. DNAN concentration in the blank solutions did not change significantly over $120 \mathrm{~h}$ and the slope of $\ln \left(\mathrm{C} / \mathrm{C}_{0}\right)$ was not different from zero (Fig. s2). For samples with soils, a sharp drop in DNAN concentration in the first hours was followed by a steady decrease over time. Adsorption equilibrium was attained by $24 \mathrm{~h}$ for all 
soils except Sassafras loam, for which $48 \mathrm{~h}$ was required. We chose to conduct all isotherm experiments using a 24-h equilibration time for easy comparison between the soils.

Table 2. Measured physical and chemical properties of soils used in experiments (Mark et al., 2016).

\begin{tabular}{|c|c|c|c|c|c|c|c|c|c|c|}
\hline Soil & Texture & Clay & Silt & Sand & $\mathrm{pH}^{\mathrm{a}}$ & $\mathrm{EC}^{\mathrm{b}}$ & $\mathrm{SSA}^{\mathrm{c}}$ & $\mathrm{OC}^{\mathrm{d}}$ & $\mathrm{CEC}^{8.2 \mathrm{e}}$ & Mineralogy \\
\hline & & $\%$ & $\%$ & $\%$ & & & $\mathrm{~m}^{2} \mathrm{~g}^{-1}$ & $\%$ & $\mathrm{cmol}_{\mathrm{c}} \mathrm{kg}^{-1}$ & \\
\hline Catlin & silt loam & 25.6 & 65.5 & 8.9 & 7.31 & 492 & 6.4 & 5.28 & 21.4 & $\mathrm{~S}, \mathrm{M}, \mathrm{K}, \mathrm{Q}$ \\
\hline $\begin{array}{l}\text { Fort } \\
\text { Harrison }\end{array}$ & $\begin{array}{l}\text { sandy } \\
\text { loam }\end{array}$ & 8.7 & 36.5 & 54.9 & 6.67 & 449 & 7.4 & 3.88 & 18 & $\mathrm{~V}, \mathrm{M}, \mathrm{K}, \mathrm{C}$ \\
\hline $\begin{array}{l}\text { Arnold } \\
\text { AFB }\end{array}$ & silt loam & 11.4 & 65.5 & 23.1 & 6.66 & 131 & 7.8 & 2.68 & 8.7 & HIV, K, Q, C \\
\hline Plymouth & $\begin{array}{l}\text { loamy } \\
\text { sand }\end{array}$ & 4.4 & 20.4 & 75.2 & 4.23 & 206 & 1.7 & 2.45 & 6.8 & $\mathrm{~V}, \mathrm{~K}$ \\
\hline $\begin{array}{l}\text { Camp } \\
\text { Butner }\end{array}$ & $\begin{array}{l}\text { sandy } \\
\text { loam }\end{array}$ & 7.7 & 25.9 & 66.4 & 6.69 & 219 & 4.8 & 2.42 & 6.1 & $\mathrm{~K}, \mathrm{~V}, \mathrm{HIV}, \mathrm{Q}, \mathrm{M}$ \\
\hline $\begin{array}{l}\text { Limestone } \\
\text { Hills }\end{array}$ & $\begin{array}{l}\text { sandy } \\
\text { loam }\end{array}$ & 11.2 & 35.7 & 53.1 & 7.54 & 539 & 10.5 & 1.99 & 13 & $\mathrm{~K}, \mathrm{M}, \mathrm{C}, \mathrm{S}, \mathrm{Q}$ \\
\hline Sassafras & loam & 16.4 & 42.3 & 41.4 & 4.4 & 212 & 7.17 & 1.30 & 7.9 & $\mathrm{~K}, \mathrm{HIV}, \mathrm{M}, \mathrm{C}$ \\
\hline $\begin{array}{l}\text { Camp } \\
\text { Gruber }\end{array}$ & $\begin{array}{l}\text { clay } \\
\text { loam }\end{array}$ & 32.3 & 44.9 & 22.8 & 5.39 & 74 & 38.3 & 0.83 & 14.3 & $\mathrm{~S}, \mathrm{~K}, \mathrm{M}, \mathrm{Q}$ \\
\hline $\begin{array}{l}\text { Camp } \\
\text { Guernsey }\end{array}$ & loam & 4.1 & 12.5 & 83.4 & 8.21 & 477 & 3.9 & 0.77 & 2.9 & $\mathrm{~S}, \mathrm{M}, \mathrm{K}, \mathrm{C}, \mathrm{Q}$ \\
\hline $\begin{array}{l}\text { Florence } \\
\text { MR }\end{array}$ & loam & 26.8 & 33.5 & 39.7 & 8 & 417 & 33 & 0.45 & 12.2 & $\mathrm{~S}, \mathrm{M}, \mathrm{K}, \mathrm{Q}$ \\
\hline $\begin{array}{l}\text { Camp } \\
\text { Swift }\end{array}$ & $\begin{array}{l}\text { sandy } \\
\text { clay } \\
\text { loam }\end{array}$ & 23.7 & 20.8 & 55.6 & 7.83 & 203 & 15.1 & 0.34 & 6.5 & $\mathrm{~K}, \mathrm{M}, \mathrm{S}, \mathrm{Q}$ \\
\hline
\end{tabular}

${ }^{a}$ In 1:1 soil:water;

${ }^{\mathrm{b}} \mathrm{EC}=$ Electrical conductivity;

${ }^{c} \mathrm{SSA}=$ specific surface area;

${ }^{\mathrm{d}} \mathrm{OC}=$ organic carbon;

${ }^{\mathrm{e}} \mathrm{CEC} 8.2$ = cation exchange capacity at $\mathrm{pH} 8.2$;

${ }^{\mathrm{f}}$ Mineralogy, listed in order of decreasing content: $\mathrm{C}=$ chlorite, HIV $=$ hydroxyl-interlayered vermiculite, $\mathrm{K}=$ kaolinite, $\mathrm{M}=$ mica, $\mathrm{Q}=$ quartz, $\mathrm{S}=$ smectite, $\mathrm{V}=$ vermiculite 
Table 3. Fate and transport parameters for DNAN: linear adsorption coefficient, $K_{d}$; adsorption coefficient normalized to fraction of organic carbon in soils, $K_{O C}$; retardation factor for linear sorption $R$; Freundlich adsorption parameters, $K_{f}$ and $n$; linearized adsorption coefficient, $K_{d}^{\mathrm{L}}$; linearized adsorption coefficient normalized to fraction of organic carbon in soils, $K_{o c}^{\mathrm{L}}$; retardation factors for Freundlich sorption, $R_{f} 0.5$ and $R_{f 50}$ calculated for $0.5 \mathrm{mg} \mathrm{L}^{-1}$ and $50 \mathrm{mg} \mathrm{L}^{-1}$ DNAN concentrations, respectively; mass-loss rate coefficient, $k$; half-lives for DNAN; $\mathrm{t}_{1 / 2} ; \mathrm{R}^{2}$ values; and $95 \%$ confidence intervals $(\mathrm{CI})$. All fits for adsorption isotherms were highly significant $(\mathrm{P}$-value $\leq 0.01)$, significance of the $k$ estimates is indicated in the table (Sig.).

\begin{tabular}{|c|c|c|c|c|c|c|c|c|c|c|c|c|c|c|c|c|c|c|c|}
\hline \multirow{2}{*}{ Soils } & \multicolumn{2}{|c|}{$K_{d}$} & \multirow[t]{2}{*}{$\mathrm{R}^{2}$} & \multirow[t]{2}{*}{$K_{d}^{L}$} & \multirow[t]{2}{*}{$K_{o c}$} & \multirow[t]{2}{*}{$K_{o c}^{L}$} & \multirow[t]{2}{*}{$R$} & \multicolumn{2}{|c|}{$K_{f}$} & \multicolumn{2}{|l|}{$n$} & \multirow[t]{2}{*}{$R_{f 0.5}$} & \multirow[t]{2}{*}{$R_{f 50}$} & \multirow[t]{2}{*}{$\mathrm{R}^{2}$} & \multicolumn{2}{|c|}{$k$} & \multirow[t]{2}{*}{$\mathrm{t}_{1 / 2}$} & \multirow[t]{2}{*}{$\mathrm{R}^{2}$} & \multirow[t]{2}{*}{ Sig. } \\
\hline & Mean & $\begin{array}{c}95 \% \\
\text { CI }\end{array}$ & & & & & & Mean & $\begin{array}{c}95 \% \\
\text { CI }\end{array}$ & Mean & $\begin{array}{l}95 \% \\
\text { CI }\end{array}$ & & & & Mean & $\begin{array}{c}95 \% \\
\text { CI }\end{array}$ & & & \\
\hline & $\mathrm{L} \mathrm{kg}^{-1}$ & & & & $\mathrm{~L} \mathrm{~kg}^{-1}$ & & & $m g^{1-n} L^{n} k$ & & & & & & & & & $\mathrm{~d}$ & & \\
\hline Catlin & 6.0 & 1.1 & 0.92 & 7.7 & 112.7 & 145.6 & 21.2 & 34 & 4.4 & 0.62 & 0.04 & 94 & 17.2 & 0.98 & 0.003 & 0.0024 & 9.6 & 0.85 & $*$ \\
\hline Fort Harrison & 6.3 & 0.6 & 0.93 & 5.7 & 162.9 & 145.7 & 27.5 & 13.9 & 4.2 & 0.77 & 0.12 & 53.7 & 19.3 & 0.9 & 0.0004 & 0.0026 & 72.2 & 0.08 & $\mathrm{~ns}$ \\
\hline Arnold AFB & 3.4 & 0.5 & 0.78 & 4.1 & 126.5 & 153.7 & 12.5 & 14.4 & 3.5 & 0.68 & 0.09 & 42.4 & 10.5 & 0.93 & 0.0016 & 0.001 & 18.0 & 0.90 & $* *$ \\
\hline Plymouth & 4.4 & 0.6 & 0.94 & 5.2 & 178.6 & 212.0 & 19.1 & 10.1 & 1.8 & 0.83 & 0.08 & 40 & 18.8 & 0.98 & 0.0068 & 0.0023 & 4.2 & 0.96 & $* *$ \\
\hline Camp Butner & 2.1 & 0.3 & 0.92 & 2.8 & 84.8 & 113.8 & 9.6 & 15.4 & 3.7 & 0.56 & 0.09 & 50.1 & 7.5 & 0.91 & 0.0006 & 0.0019 & 48.1 & 0.22 & $\mathrm{~ns}$ \\
\hline $\begin{array}{l}\text { Limestone } \\
\text { Hills }\end{array}$ & 5.0 & 0.6 & 0.92 & 4.4 & 250 & 220.7 & 21.8 & 10.8 & 2.1 & 0.77 & 0.07 & 41.9 & 15.2 & 0.96 & 0.0025 & 0.0022 & 11.5 & 0.76 & $*$ \\
\hline Sassafras & 1.9 & 0.4 & 0.72 & 2.0 & 228.3 & 157.3 & 8.5 & 2.3 & 1.1 & 0.97 & 0.2 & 10.1 & 8.9 & 0.85 & 0.0009 & 0.0034 & 32.1 & 0.21 & $\mathrm{~ns}$ \\
\hline Camp Gruber & 2.0 & 0.3 & 0.91 & 2.5 & 240.6 & 306.2 & 7.6 & 7.6 & 2.7 & 0.72 & 0.15 & 23.2 & 7.1 & 0.84 & 0.0003 & 0.0017 & 96.3 & 0.06 & $\mathrm{~ns}$ \\
\hline $\begin{array}{l}\text { Camp } \\
\text { Guernsey }\end{array}$ & 0.9 & 0.1 & 0.97 & 0.9 & 121.4 & 122.8 & 4.7 & 1.7 & 0.6 & 0.85 & 0.16 & 7.4 & 4.2 & 0.93 & 0.0033 & 0.0012 & 8.8 & 0.96 & $* *$ \\
\hline Florence MR & 1.9 & 0.3 & 0.94 & 2.4 & 424.4 & 530.4 & 8.6 & 6.6 & 1.2 & 0.74 & 0.06 & 24.3 & 8.1 & 0.98 & 0.0002 & 0.0025 & 144.4 & 0.03 & $\mathrm{~ns}$ \\
\hline Camp Swift & 0.6 & 0.2 & 0.84 & 0.7 & 175.5 & 204.5 & 3.6 & 1.3 & 0.7 & 0.84 & 0.26 & 6.2 & 3.5 & 0.7 & 0.0006 & 0.0003 & 48.1 & 0.91 & $* *$ \\
\hline
\end{tabular}


The change in DNAN concentration over time after adsorption equilibrium followed $1^{\text {st }}$ order kinetics. This behavior is attributed to transformation and/or irreversible adsorption, as discussed below. The first order mass-loss rate coefficients ranged between 0.0002 and $0.0068 \mathrm{~h}^{-}$

${ }^{1}$ (half life of 144 to 4 days) for Florence and Plymouth soils, respectively (Table 3). The $k$ values were not significantly correleated with soil parameters such as, $\mathrm{pH}, \mathrm{OC}, \mathrm{SSA}, \mathrm{CEC}$, and clay content. No known products of DNAN tranformation were measured in solution.

\section{DNAN mass balance}

Mass balance studies evaluated the recovery of DNAN in solution and in soil for sterilized and unsterilized Catlin silt loam and Sassafras loam soils equilibrated for 24 and 120 hours (Fig. 1). Catlin and Sassafras were selected to determine mass balance because they differed significantly in a number of properties that are commonly associated with sorption behavior, such as $\mathrm{OC}$ and clay content, and $\mathrm{pH}$ of soil solution (Table 2). A full or close to full recovery was observed at $24 \mathrm{~h}$ for both soils with or without sterilization (Fig.1, Table s2). However, sterilized soils adsorbed less DNAN (difference significant for $24 \mathrm{~h}$ for both soils) (Table s2), possibly as a result of the impact of autoclaving on soil properties and resultant influence on adsorption (e.g., Xie and Mackenzie, 1991; Lotrario et al., 1995). The complete mass balance of DNAN obtained at $24 \mathrm{~h}$ means that calculation of sorbed concentrations and $K_{d}$ values from measures of solution-phase concentrations only are valid.

Complete DNAN recovery was not obtained at $120 \mathrm{hr}$ for either of the studied soils for the unsterilized treatment. The smaller recoveries could be the result of transformation, both abiotic and biotic, irreversible adsorption, or some combination thereof. Known transformation products were not observed in solution. 

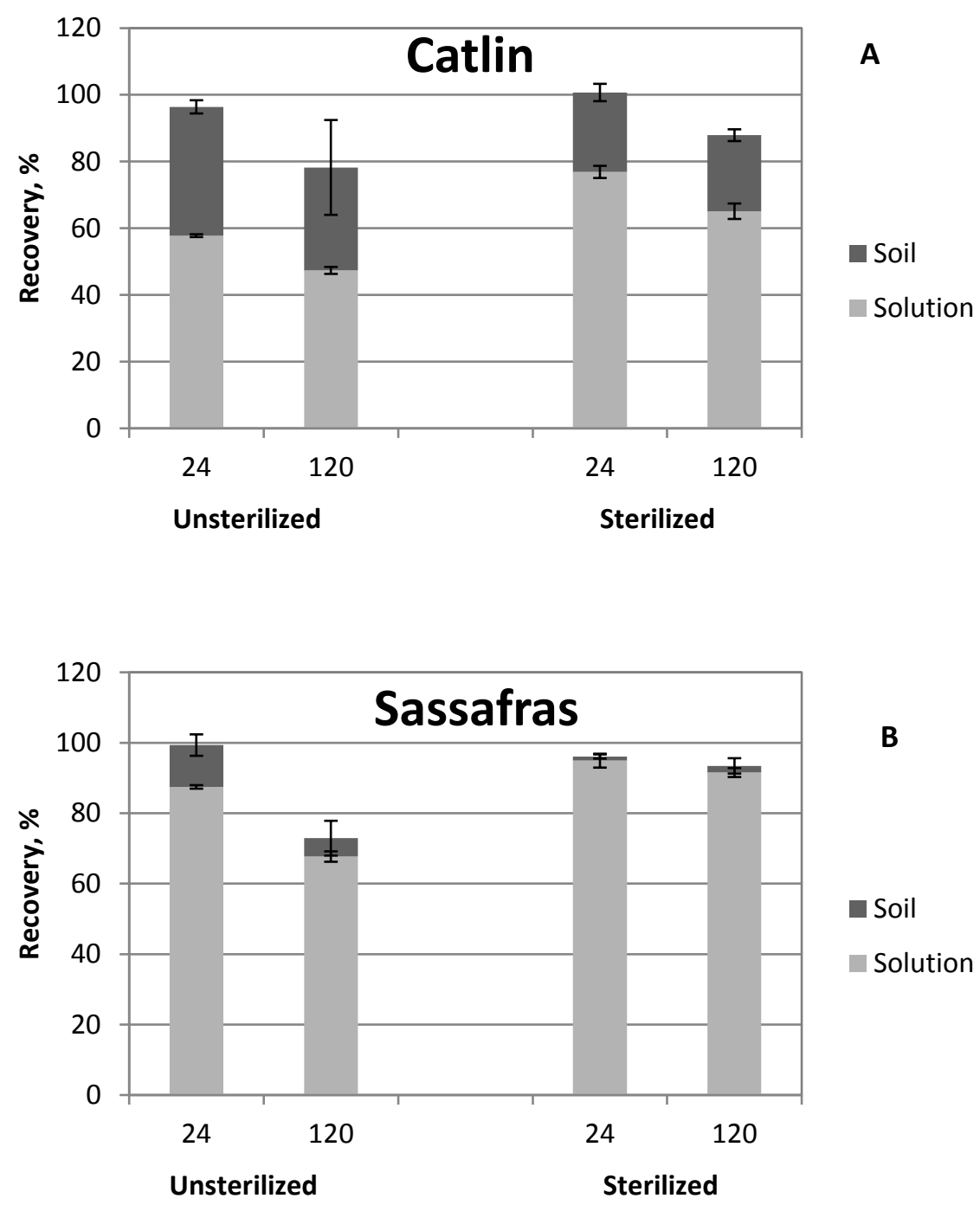

Figure 1. Mass balance of DNAN in unsterilized and sterilized Catlin (A) and Sassafras (B) soils for 24 and 120 hours of contact. Soil to solution ratio was 1:60 for both soils. Error bars equal confidence interval of the mean (Table s2).

The 24-hr and 120-hr recoveries were similar for the sterilized Sassafras soil, and were close to $100 \%$. In addition, the 120 -hr recovery for the unsterilized treatment was lower than for the sterilized treatment. These results indicate that the significant mass loss observed for the unsterilized Sassafras soil treatment is due almost exclusively to biotic transformation, with minor impacts of abiotic transformation or irreversible adsorption. Conversely, for the Catlin 
soil, the 120 -hr recovery is lower than the 24 -hr recovery for the sterilized treatment. This indicates a contribution of abiotic transformation and/or irreversible adsorption. Since Catlin soil has higher OC and clay content than Sassafras and clay fraction in Catlin is dominated by expandable clays, both of these can potentially contribute to irreversible adsorption of DNAN.

\section{Adsorption isotherms}

All studied soils adsorbed DNAN and the magnitude of adsorption depended on the properties of the soil. The $K_{d} \mathrm{~s}$ ranged from 0.6 to $6.3 \mathrm{~L} \mathrm{~kg}^{-1}$ and $\mathrm{K}_{f} \mathrm{~s}$ ranged from 1.3 to $34 \mathrm{mg}^{1-\mathrm{n}}$ $\mathrm{L}^{\mathrm{n}} \mathrm{kg}^{-1}$, while linearized $K_{d}{ }^{L}$ for $50 \mathrm{mg} \mathrm{L}^{-1}$ DNAN solution ranged between 0.7 and $7.7 \mathrm{~L} \mathrm{~kg}^{-1}$. The estimated retardation factors ranged between 3.6 and 27.5 for linear sorption (Table 3 ) and between 3.5 and 94 depending on the concentration for Freundlich sorption indicating potentially significant retardation of DNAN in soil during transport. Catlin and Fort Harrison soils with high OC and CEC absorbed more DNAN from solution and had the highest retardation factors. Conductivity and $\mathrm{pH}$ of soil suspensions was not significantly affected by addition of DNAN (not shown).

Both linear and Freundlich isotherms resulted in highly significant fits to the measured data (Fig. 2). The parameter $n$, the exponent in the Freundlich equation, ranged between 0.56 and 0.97. The $95 \%$ confidence intervals of $n$ estimates overlapped for several of the soils and for Sassafras, Camp Guernsey and Camp Swift, $n$ was not significantly different from 1 (linear isotherm) (Table 3, Fig. s3). DNAN adsorption was best described by the Freundlich isotherm for a majority of the soils, however, for five soils, Camp Butner, Camp Guernsey, Camp Gruber, Fort Harrison, and Camp Swift the linear isotherm resulted in a better fit to the data based on $\mathrm{R}^{2}$ value (Table 3). Linear regressions were highly significant, with $K_{d}$ values different from zero. Estimated $\log K_{O C}\left(K_{d}\right.$ normalized to OC) equaled $2.24 \pm 0.20$ and $\log K_{O C}{ }^{L}$ equaled $2.27 \pm 0.19$. 

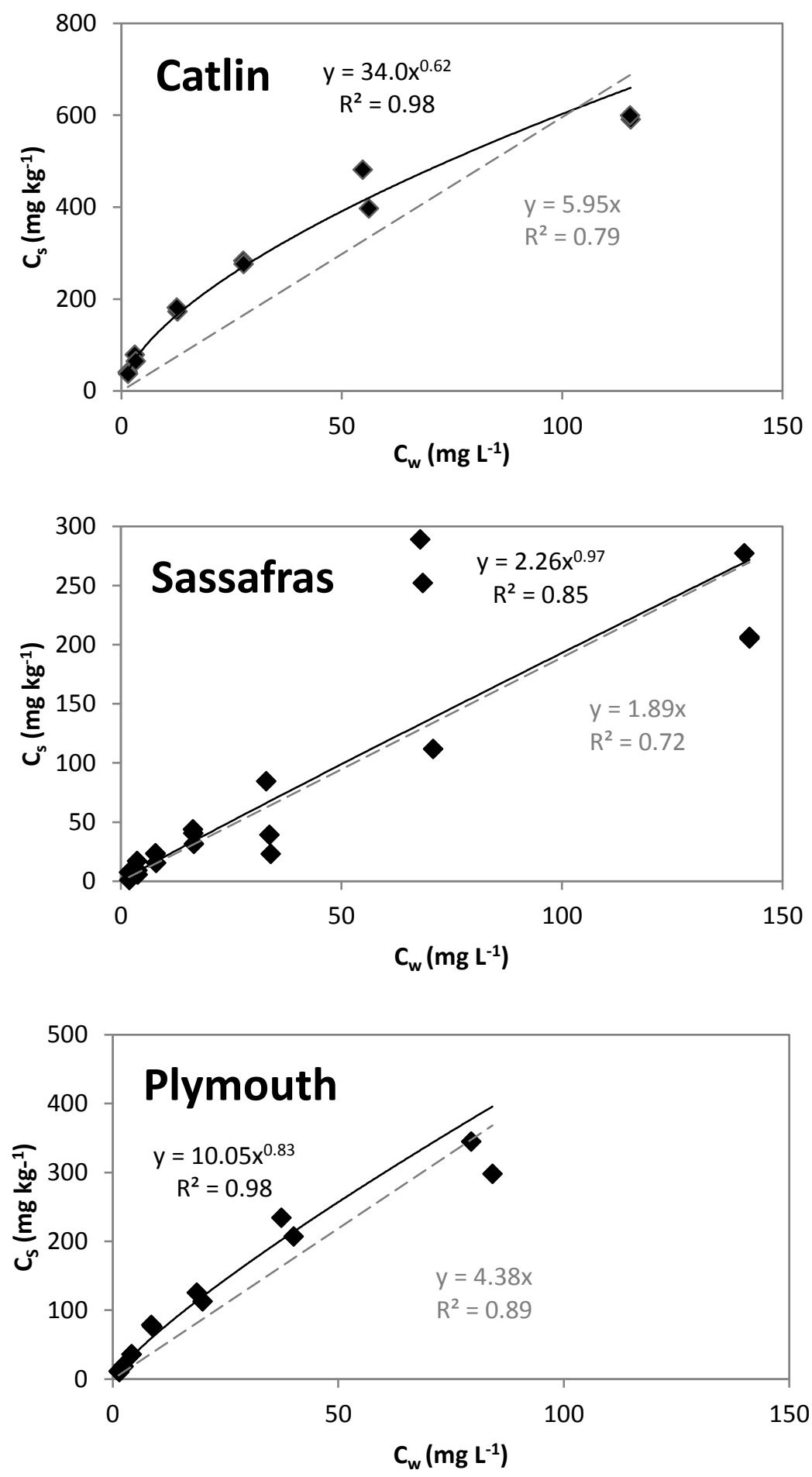

Figure 2. Adsorption isotherms calculated for DNAN in Catlin, Sassafras, and Plymouth soils.

Grey dashed line indicates linear adsorption isotherm fit to the measured adsorption data (equation is in grey), while solid black line is a fit of the Freundlich isotherm (equation in black). 

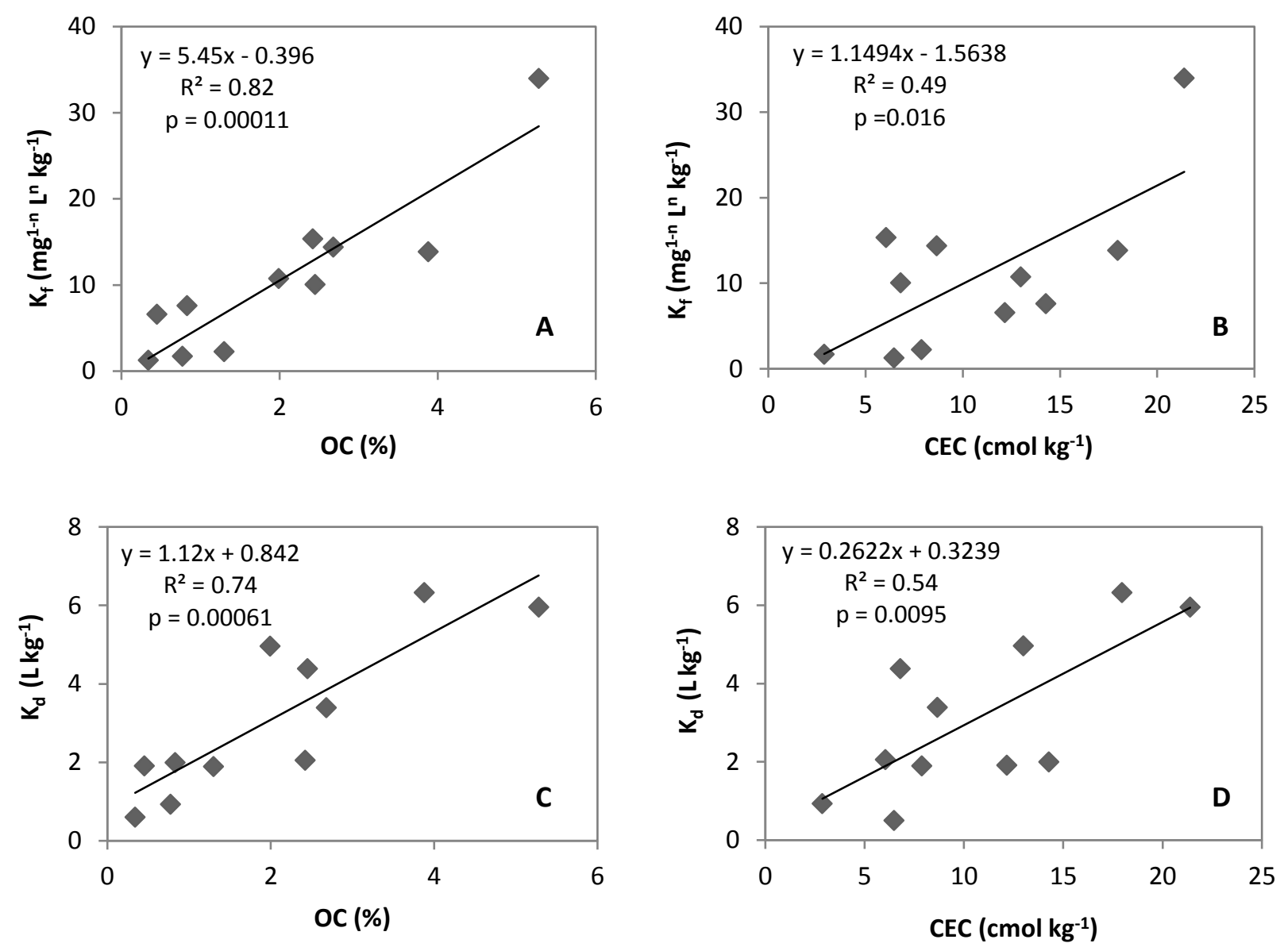

Figure 3. Correlation between measured DNAN Freundlich adsorptions coefficients $\left(K_{f} \mathrm{~s}\right)$ and percent organic carbon in soil (OC) (A); cation exchange capacity (CEC) (B); and linear adsorptions coefficients $\left(K_{d} \mathrm{~s}\right)$ and soil OC (C); CEC (D). All relationships were significant at 95\% confidence level.

\section{Transport studies}

Breakthrough of the conservative tracer (Fig. 4 and 5) occurred at 1 pore volume (2.33 h), which indicates there was no preferential flow or air entrainment in the columns. The curves were sharp and symmetrical, indicating ideal advective/dispersive transport. Longitudinal dispersivity values ranged from $\sim 0.1$ to $\sim 3 \mathrm{~cm}$ (Table 4 ).

Figures 4 and 5 show sample DNAN breakthrough curves for Camp Swift and Camp Guernsey soils. DNAN breakthrough was observed later than the conservative tracer bromide 
indicating adsorption to the solid phase. DNAN transformation product 2-ANAN was observed in all continuous and flow interruption experiments, while 4-ANAN was only observed in Camp Guernsey soil experiments. 2-ANAN and 4-ANAN both exhibited retardation. Continuous flow breakthrough curves for Camp Swift soil were symmetrical (Fig. 4), while in Camp Guernsey soil DNAN and its daughter compounds exhibited more complex behavior (Fig. 5): effluent concentrations of DNAN decreased over time while 2-ANAN and 4-ANAN either continued at similar concentrations or also decreased. During the flow interruption experiments for Camp Swift, effluent concentration of DNAN decreased due to continuing transformation and then increased again to a steady state value after resuming the experiment. The decrease in DNAN concentration during flow interruption was matched by an increase in 2-ANAN concentration. For Camp Guernsey soil, after the 24-hour flow interruption, no DNAN was detected but 2ANAN concentration increased. This observed behavior is consistent with the impact of transformation reactions on transport.

For Camp Swift soil, the $K_{d}$ values estimated using HYDRUS-1D $\left(1.22 \pm 0.14 \mathrm{~L} \mathrm{~kg}^{-1}\right)$ and TMA $\left(1.71 \pm 0.36 \mathrm{~L} \mathrm{~kg}^{-1}\right)$ for DNAN were not statistically different from each other. However, they are higher than the estimated $K_{d}$ from the batch experiments $\left(0.60 \pm 0.09 \mathrm{~L} \mathrm{~kg}^{-1}\right)$ (Table 4). These parameters could not be determined by HYDRUS-1D for Camp Guernsey column experiments, but, $K_{d}$ s determined by TMA $\left(1.13 \pm 0.19 \mathrm{~L} \mathrm{~kg}^{-1}\right)$ were similar to the estimated $K_{d}$ determined by batch experiments for DNAN in Camp Guernsey soil $(0.85 \pm 0.17 \mathrm{~L}$ $\left.\mathrm{kg}^{-1}\right)$. The average DNAN retardation factors calculated using TMA were 8.5 for Camp Swift soil and 5.9 for Camp Guernsey. 

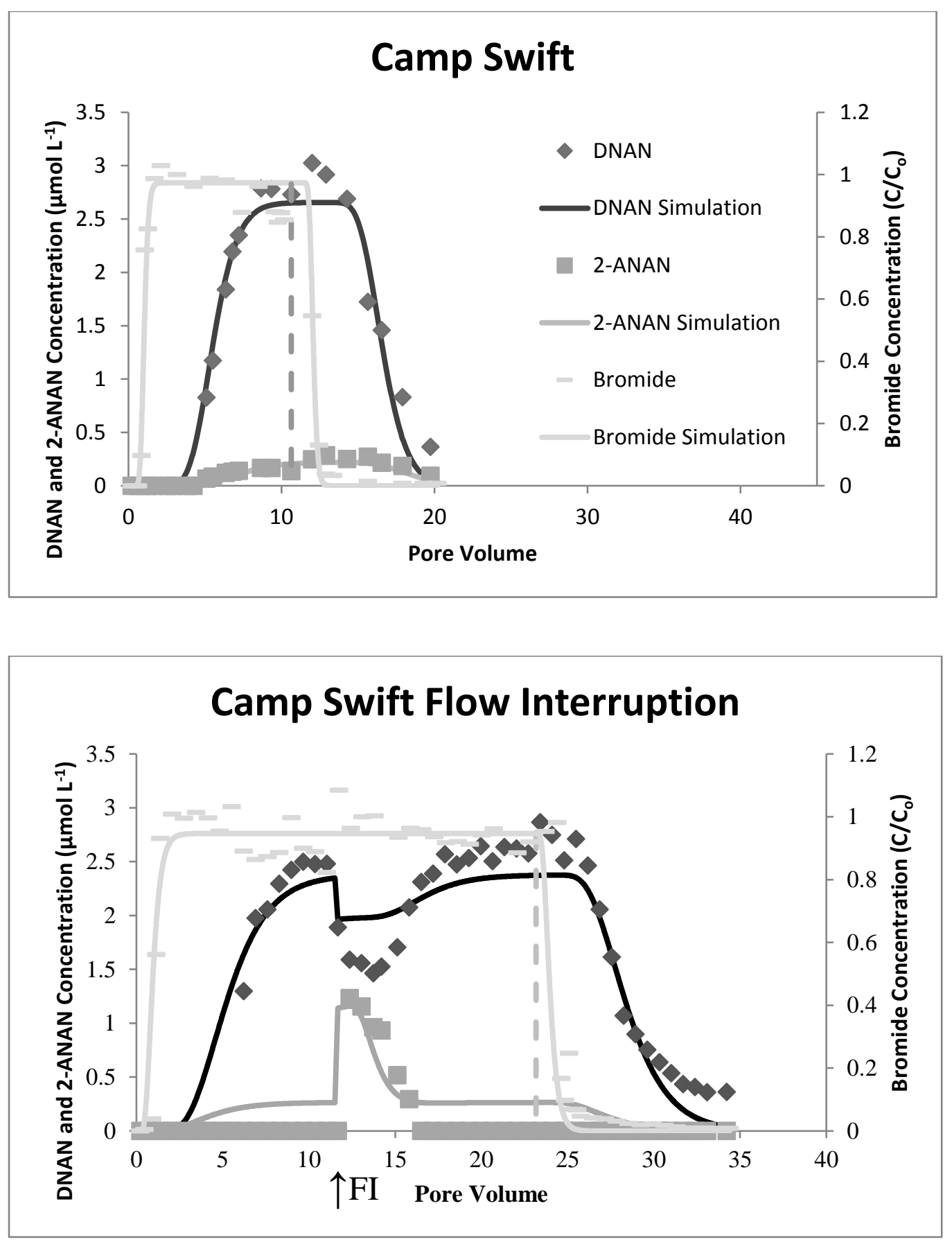

Figure 4. Measured (markers) and HYDRUS-1D simulated (lines) breakthrough curves for $\mathrm{Br}^{-1}$, DNAN and 2-ANAN in Camp Swift soil for continuous flow and flow interruption (FI). DNAN inflow concentration was $2.87 \mu \mathrm{mol} \mathrm{L}{ }^{-1}$ and $2.64 \mu \mathrm{mol} \mathrm{L}^{-1}$ respectively for continuous and interrupted flow experiments. Arrow indicates time of flow interruption and dashed line indicates time when input solution was switched back to background. 

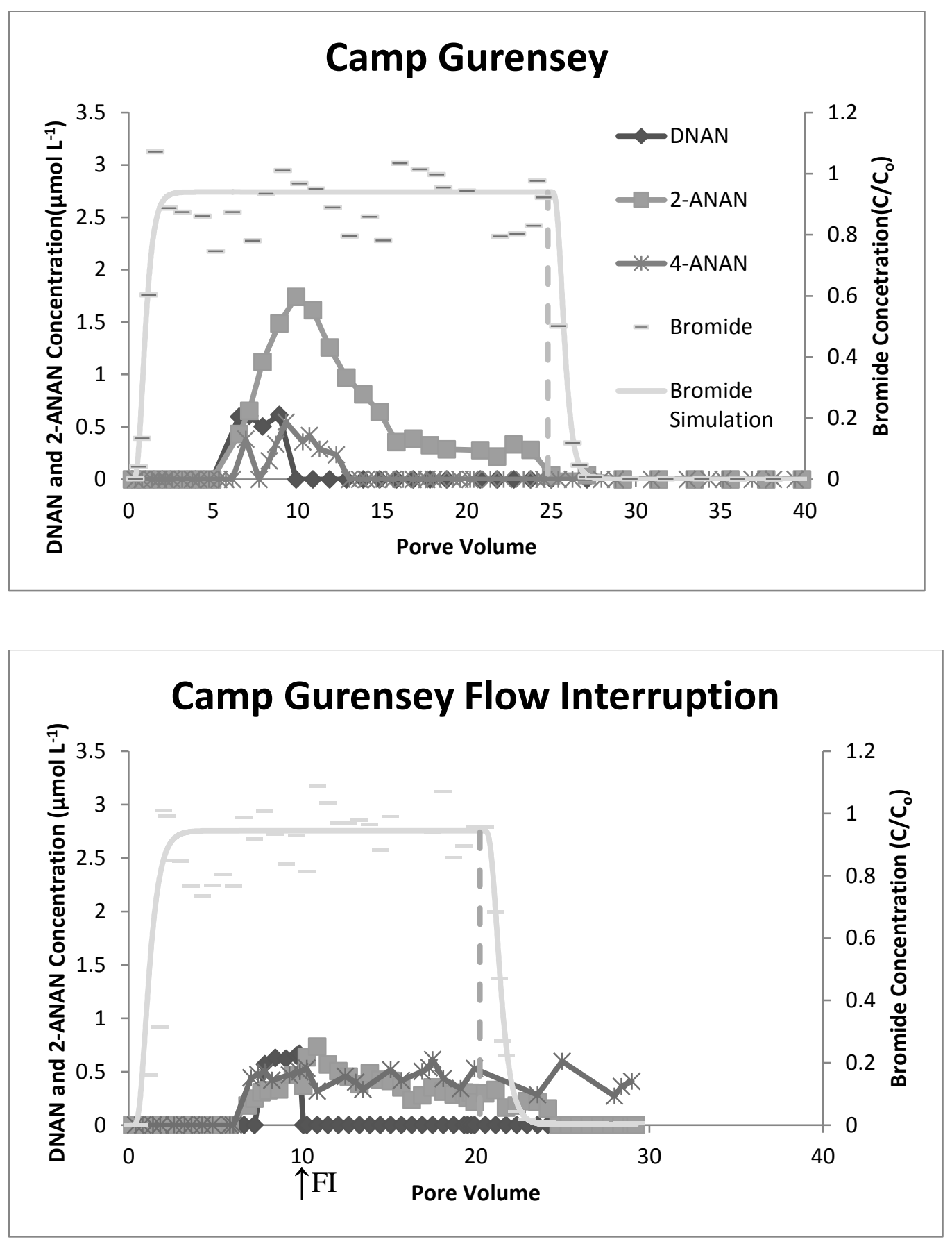

Figure 5. Measured breakthrough curves for DNAN and 2-ANAN, and measured and simulated curves for $\mathrm{Br}^{-1}$, in Camp Guernsey soil for continuous flow and flow interruption (FI). DNAN inflow concentration was $2.71 \mu \mathrm{mol} \mathrm{L}^{-1}$ and $2.78 \mu \mathrm{mol} \mathrm{L}^{-1}$ respectively for continuous and interrupted flow experiments. Arrow indicates time of flow interruption and dashed line indicates time when input solution was switched back to background. 
Estimated mass-loss rate coefficients, $k$, determined by HYDRUS-1D $\left(0.046 \pm 0.021 \mathrm{~h}^{-1}\right)$ and TMA $\left(0.053 \pm 0.016 \mathrm{~h}^{-1}\right)$ (Table 4) for DNAN in Camp Swift soil were not statistically different according to a single factor ANOVA $(\mathrm{P}=0.6)$. However, the mass-loss rate coefficients were higher than values for batch experiment data $\left(0.0006 \pm 0.0003 \mathrm{~h}^{-1}\right)$. This agrees with the fact that no transformation products of DNAN were observed in the batch experiments. TMA estimates for mass-loss rate coefficients for Camp Guernsey $\left(0.421 \pm 0.088 \mathrm{~h}^{-1}\right)$ were higher than the batch study results $\left(0.0033 \pm 0.0011 \mathrm{~h}^{-1}\right)$, as well. A $K_{d}$ value of $1.09 \pm 0.72 \mathrm{~L} \mathrm{~kg}^{-1}$ was obtained for 2-ANAN in Camp Swift soil from application of HYDRUS-1D; 2-ANAN $k$ values were not significantly different from zero.

\section{DNAN mass balance in transport studies}

DNAN added to the columns in solution was recovered in column effluent and soil extracts as parent compound, as well as products of its reduction, 2-ANAN and 4-ANAN. Mass balance calculations (Table 5) indicate that for Camp Swift soil on average all of the DNAN (mean \pm CI: $102.0 \pm 8.4 \%$ ) was recovered as parent compound and 2-ANAN. For Camp Guernsey soil, approximately half of DNAN was recovered (50.7 $\pm 20.7 \%)$. There was no significant difference in total recoveries between interrupted and continuous flow experiments for either soil.

\section{DISCUSSION}

This study examined the fate (adsorption and mass loss) of DNAN in eleven soils collected from training ranges across the United States. The results are assessed and compared to TNT, a common and similar munitions compound. Implications of the correlations between fate and transport parameters and soil properties for DNAN are discussed, as is the potential that they may provide a tool for estimating these parameters for other soils. 
Table 4. Comparison of fate and transport parameters, longitudinal dispersivities, $\lambda$, linear adsorption coefficients, $K_{d}$, and mass-loss rate coefficients, $k$, for DNAN and 2-ANAN determined from HYDRUS-1D and temporal moment analysis (TMA).

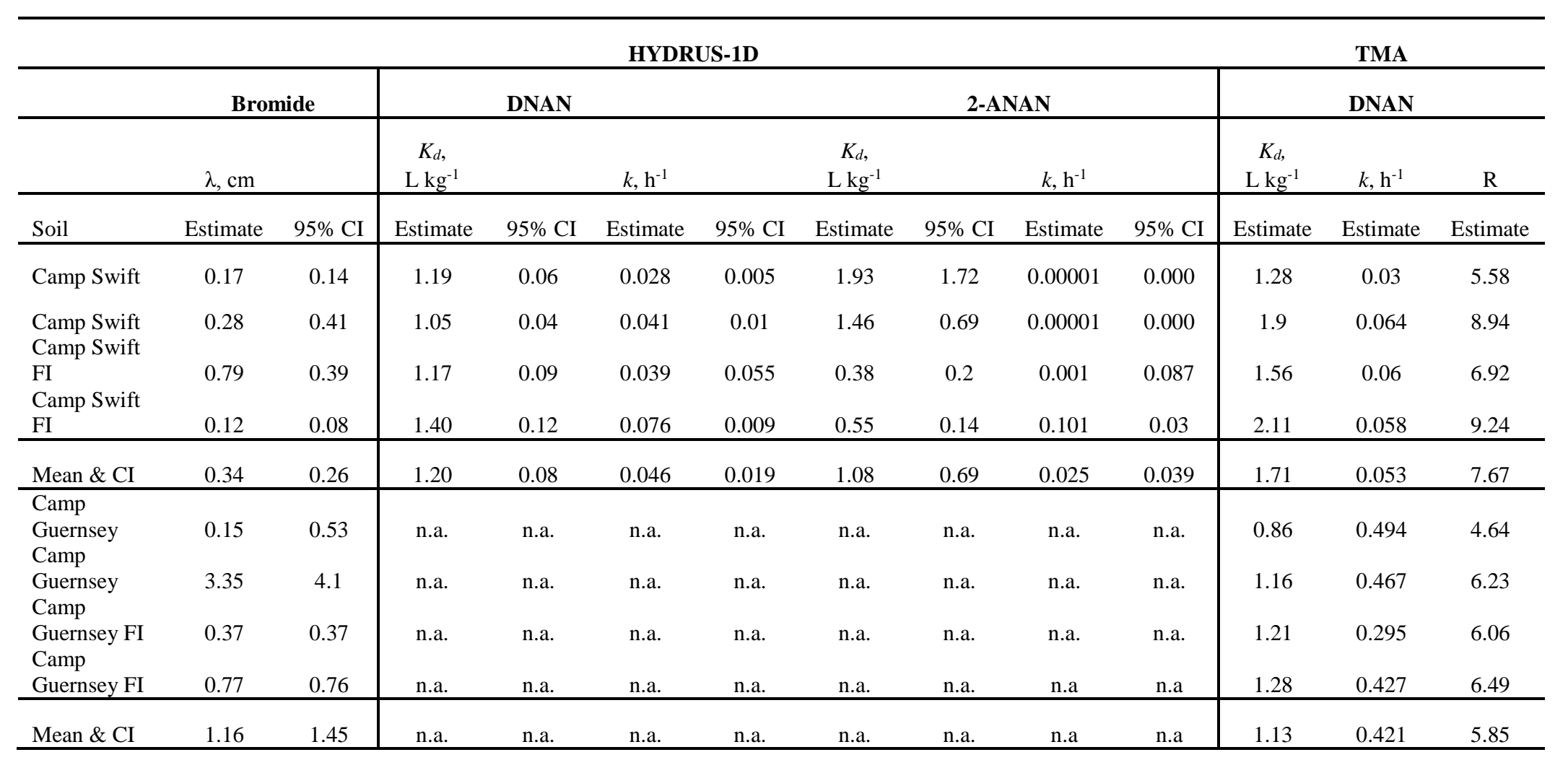

Note: Bulk density $(\rho)$ was determined by the mass of the air-dried soil used to pack the column and saturated water content $(\theta)$ was determined from the weight of the water need to saturate the column. The estimated bulk density for Camp Swift was $1.54 \pm 0.02$ and saturated water content $0.40 \pm 0.02$. Camp Guernsey estimated bulk density was $1.62 \pm 0.02$ and saturated water $0.38 \pm 0.01$. n.a- data not available from HYDRUS. 
Table 5. Mass of added DNAN recovered in effluent and in soil during column transport experiments $(\%) . \mathrm{FI}=$ flow interruption for 24 hours.

\begin{tabular}{lccccccr}
\hline & \multicolumn{2}{c}{ Solution recoveries, \% } & \multicolumn{2}{c}{ Soil recoveries, \% } & \multicolumn{2}{c}{ Total, \% } \\
\cline { 2 - 7 } Soil & DNAN & 2-ANAN & 4-ANAN & DNAN & 2-ANAN & 4-ANAN & $\begin{array}{r}\text { (solution } \\
\text { +soil) }\end{array}$ \\
\hline Camp Swift & 91.9 & 8.5 & 0.0 & 8.0 & 4.0 & 1.8 & 114.2 \\
Camp Swift & 85.0 & 10.3 & 0.0 & 4.5 & 0.0 & 1.9 & 101.7 \\
Camp Swift FI & 83.0 & 4.0 & 0.0 & 4.5 & 4.0 & 1.9 & 97.4 \\
Camp Swift FI & 59.3 & 21.6 & 0.0 & 5.8 & 5.2 & 2.9 & 94.8 \\
\hline $\begin{array}{l}\text { Mean } \\
\text { CI }\end{array}$ & 79.8 & 11.1 & 0.0 & 5.7 & 3.3 & 2.1 & 102.0 \\
\hline $\begin{array}{l}\text { Camp } \\
\text { Guernsey }\end{array}$ & 13.9 & 7.3 & 0.0 & 1.6 & 2.2 & 0.5 & 8.4 \\
$\begin{array}{l}\text { Camp } \\
\text { Guernsey }\end{array}$ & 3.4 & 19.5 & 0.9 & 0.0 & 4.7 & 4.2 & 32.7 \\
$\begin{array}{l}\text { Camp } \\
\text { Guernsey FI }\end{array}$ & 4.8 & 24.9 & 28.6 & 7.2 & 9.0 & 5.7 & 80.2 \\
$\begin{array}{l}\text { Camp } \\
\text { Guernsey FI }\end{array}$ & 5.9 & 24.0 & 11.4 & 2.3 & 11.4 & 3.9 & 58.8 \\
\hline $\begin{array}{l}\text { Mean } \\
\text { CI }\end{array}$ & 2.0 & 11.7 & 44.1 & 1.2 & 0.5 & 6.3 & 65.9 \\
\hline
\end{tabular}

Adsorption coefficients ranged widely as would be expected for a diverse group of soils selected. Comparing these coefficients to TNT adsorption coefficients for Plymouth and Catlin soils showed higher adsorption of DNAN in Plymouth $\left(K_{d}\right.$ of $4.4 \mathrm{~L} \mathrm{~kg}^{-1}$ for DNAN and 0.63-1.6 $\mathrm{L} \mathrm{kg}^{-1}$ for TNT depending on the method used) (Dontsova et al., 2006) and Catlin soils $\left(K_{f}=\right.$ 45.6, $\mathrm{n}=0.57$ for DNAN and $K_{f}=32.67, \mathrm{n}=0.60$ for TNT) (Dontsova et al., 2009). Hawari et al. (2015) demonstrated a link between solubility, octanol-water partition coefficient $\left(K_{\text {ow }}\right)$, and $K_{O C}$ for DNAN, for several of its transformation products, and for TNT. Solubility followed the following order: TNT $<$ DNAN $<2$-ANAN $<4$-ANAN $<$ DAAN whereas $\log K_{o w}$ and $K_{O C}$ 
followed the reverse order DAAN $<4$-ANAN $<2$-ANAN $<$ DNAN $<$ TNT, so TNT had the lower solubility and the higher $K_{o w}$ and $K_{O C}$ than DNAN. Therefore, they predicted that DNAN would be slightly more mobile than TNT in soil.

Our estimated mean $\log K_{O C}\left(K_{d}\right.$ normalized to OC) for DNAN was $2.24 \pm 0.20$, a value similar to one estimated for DNAN by Hawari et al. (2015) (2.45 \pm 0.16$)$, but also to values for TNT in soils (2.48-3.04) (US Department of Health and Human Services, 1995) and in water dispersible clay extracted from soils $(2.65 \pm 0.28)$ (Dontsova et al., 2009). The low variability of $K_{O C}$ values as well as their consistent decrease with decrease in $\log K_{o w}$ implies that DNAN adsorbs to OC through hydrophobic interactions. There were strong correlations between adsorption coefficient and OC that supports this mechanism, however the non-linear shape of the isotherms (Fig. 2) best described by the Freundlich equation (Table 3) indicates that adsorption to the soils is not solely based on partitioning to organic carbon.

Previous research conducted by Erikson and Skyllberg (2001) studied the binding of TNT and its degradation products to soil organic matter, specifically looking at dissolved organic matter (DOM) and a two phase system of particulate organic matter (POM) and DOM. The results of their experiment with DOM showed that binding of TNT and its degradation products was greatly increased with increasing $\mathrm{pH}$, which indicated that negatively charged weak acid groups in DOM are involved in binding. The results of the two-phase system showed that binding of TNT and its degradation products to POM was less $\mathrm{pH}$ dependent than found for DOM. The suggested mechanism of TNT binding to POM was due to hydrophobic partitioning because the POM has a higher density of domains with hydrophobic character than DOM. We did not observe a significant relationship with $\mathrm{pH}$ for DNAN possibly due to working with whole soils that would have a mixture of different domains. 
Other researchers also suggested that TNT and other nitroaromatic compounds alike bind to organic matter by non-hydrophobic interactions. Zhang et al. (2009) who investigated the mechanism of adsorption of nitroaromatics to soils suggested that non-hydrophobic sorptive interaction between nitroaromatics and soil organic matter was primarily due to the $\pi-\pi$ interactions. Nitroaromatics are strong $\pi$ acceptors and if soil organic matter contains several aromatics rings within it structure then $\pi-\pi$ interactions/stacking can occur hence binding DNAN to the soil organic matter. Since the chemical structure of DNAN is similar to TNT and other nitroaromatic compounds, it should behave similarly in organic matter.

Linker et al. (2015) demonstrated that similarly to TNT, DNAN can be also adsorbed by phyllosilicate clays with amounts adsorbed increasing when clays are saturated with cations that are not highly hydrated, as was previously reported for nitroaromatic compounds (Haderlein et al., 1996). The mechanism of adsorption was coplanar electron donor-acceptor (EDA) formation with oxygen ligands at the external siloxane surface of clay as $\mathrm{e}^{-}$-donors and the $\pi$-system of the NACs as $\mathrm{e}^{-}$-acceptor according to Haderlein et al. (1996) and exchangeable cation-DNAN complexation or bridging according to Linker et al. (2015).

Observed correlation between DNAN adsorption coefficients and CEC confirms that both organic matter and clay adsorb DNAN, since CEC is influenced by the amount and type of clay, organic matter content of the soil (Essington, 2015), as well as interactions between these phases. The lack of the link between clay content alone and DNAN $K d$ s and $K_{f}$ s may be caused by clay fraction of the soil being composed of different minerals, only some of which are phyllosilicates, or of phyllosilicates with different reactivity.

Irrespective of the adsorption mechanism, the strong correlations that have been observed between DNAN adsorption coefficients and OC give us a good predictive capability. Since the 
soils tested from training ranges across the United States have a wide range of values for main soil properties, the strong correlation that exists between $K_{d} \mathrm{~s}$ and $K_{f} \mathrm{~s}$ and OC can be used to estimate adsorption based on measured OC for any soil.

We observed mass loss of DNAN over time in both batch and column experiments. However, measured rates and whether transformation products were detected differed. We did not detect any DNAN transformation products in solution in batch studies despite decrease in DNAN recovery at $120 \mathrm{~h}$. One explanation may be that DNAN transforms to its amino reduction products with consequent irreversible adsorption of these products to the soil organic matter. This has been observed for the DNAN and its products, ANAN and DAAN, by Hawari et al. (2015), and for TNT and DNTs, which has similar transformation pathways and structure of their reduced products, by Thorn et al. $(2002 ; 2008)$. It would be expected that this mechanism would play bigger role in DNAN fate when large amount of organic matter is available in the soil. However, in mass balance studies despite large differences in OC content between the soils there was no significant difference in the amount of DNAN unrecovered at $120 \mathrm{~h}$. It is also possible that DNAN degraded to products that were not analyzed.

In column studies, estimated mass-loss rate coefficients, $k$, were significantly higher than values determined in batch experiments. In addition we measured 2-ANAN in both soils and 4ANAN in Camp Guernsey soil. The absence of agitation in the column experiments can result in a decrease in $\mathrm{O}_{2}$ content of the solution as microorganisms consume it in respiration. If anaerobic conditions result they can promote reduction of nitro to amino groups in DNAN. However, we did not measure $\mathrm{O}_{2}$ content or redox potential of solutions, so cannot confirm this.

No relationships were observed between mass loss and any of the measured soil properties. Based on one-electron standard reduction potentials DNAN has lower tendency for 
nitro to amino group reductions than TNT (Salter-Blanc et al., 2015). The mass-loss rate for DNAN was slower than the ones previously observed for TNT in one of the studied soils. In Plymouth soil, TNT transformation rate was measured to be $0.21 \mathrm{~h}^{-1}$ (Dontsova et al., 2006) while the DNAN rate coefficient of mass loss in batch studies was $0.0068 \mathrm{~h}^{-1}$. However, measurements were done in batch study for DNAN and in column study for TNT and since experimental design was shown to affect mass-loss rate coefficients, we cannot make direct comparisons between these two values.

\section{CONCLUSION}

This study examined the adsorption and mass loss behavior of DNAN in eleven different soils, as well as its transport behavior in a subset of these soils. The equilibrium adsorption data were fitted to Freundlich and linear isotherms with the Freundlich isotherm resulting in slightly better fit on average. A strong relationship between both linear and Freundlich adsorption coefficients $\left(K_{d}\right.$ and $\left.K_{f}\right)$ and \% OC and CEC indicates that DNAN's fate would be greatly influenced by organic matter and clays in the soils. Our measured adsorption values make it possible to predict DNAN's behavior in other soils. In transport studies, we confirmed that DNAN adsorbs to soils delaying the arrival of the contaminant to the ground water by a factor of six relative to the tracer even for sandy soil with little organic carbon. We also showed that under flow conditions DNAN transforms readily to the amino products, 2-ANAN and 4-ANAN. DNAN's soil adsorption, and often significant mass loss, indicates that DNAN is naturally attenuated in the soils.

\section{SUPPLEMENTARY MATERIALS}

Supplementary materials include two tables and four figures. 


\section{ACKNOWLEDGEMENTS}

This work was funded by the Strategic Environmental Research and Development Program, SERDP, project ER-2220. We are grateful to Anthony Di Stasio and Erika Rivera, US Army Armament Research, Development and Engineering Center (ARDEC), Picatinny Arsenal for providing DNAN; Bonnie M. Packer, Rosa Gwinn, Lisa DeGrazia, Bethany Keller, Jessica Milose, Amibeth Sheridan, Laurie Stenberg, Sarah Gettier, Army National Guard-Environmental Directorate and URS Corporation, Germantown, MD and Mike Heitmann, CH2M HILL Englewood, CO for collecting soils used in the experiments on Army National Guard installations.

\section{REFERENCES}

Boddu, V., Abburi, K., Fredricksen, A., Maloney, S., Damavarapu, R., 2009. Equilibrium and column adsorption studies of 2,4-dinitroanisole (DNAN) on surface modified granular activated carbons. Environ Technol. 30, 173-181.

Boddu, V.M., Abburi, K., Maloney, S.W., Damavarapu, R., 2008. Thermophysical properties of an insensitive munitions compound, 2,4-dinitroanisole. Journal of Chemical \& Engineering Data $53,1120-1125$.

Braida, W., Strickland, D., Balas Hummers, W., Koutsospyros, A., Ogundipe, A., Su, T.-L., Tuna, G.S., Kalomoiri, A., Pavlov, J., Dhedia, D., 2011. Vadose Zone Transport of Munitions Components. US ARMY RDECOM/ARDEC, Picatinny Arsenal, New Jersey.

Brunauer, S., Emmett, P.H., Teller, E., 1938. Adsorption of gases in multimolecular layers. Journal of the American Chemical Society 60, 309-319. 
Brusseau, M.L., Hu, Q., Srivastava, R., 1997. Using flow interruption to identify factors causing nonideal contaminant transport. J. Contam. Hydrol. 24, 205-219.

Brusseau, M.L., Rao, P.S.C., Jessup, R.E., Davidson, J.M., 1989. Flow Interruption: A method for investigating sorption nonequilibrium. J. Contam. Hydrol. 4, 223-240.

Davies, P.J., Provatas, A., 2006. Characterisation of 2,4-Dinitroanisole: An Ingredient for Use in Low Sensitivity Melt Cast Formulations. Weapons Systems Division, Defence Science and Technology Organisation.

Dodard, S.G., Sarrazin, M., Hawari, J., Paquet, L., Ampleman, G., Thiboutot, S., Sunahara, G.I., 2013. Ecotoxicological assessment of a high energetic and insensitive munitions compound: 2,4dinitroanisole (DNAN). J. Hazard. Mater. 262, 143-150.

Dontsova, K.M., Hayes, C., Pennington, J.C., Porter, B., 2009. Sorption of high explosives to water-dispersible clay: Influence of organic carbon, aluminosilicate clay, and extractable iron. J. Environ. Qual. 38, 1458-1465.

Dontsova, K.M., Yost, S.L., Simunek, J., Pennington, J.C., Williford, C.W., 2006. Dissolution and transport of TNT, RDX, and Composition B in saturated soil columns. J. Environ. Qual. 35, 20432054.

Eriksson, J., Skyllberg, U., 2001. Binding of 2,4,6-trinitrotoluene and its degradation products in a soil organic matter two-phase system. J. Environ. Qual. 30, 2053-2061.

Essington, M.E., 2015. Soil and Water Chemistry: An Integrative Approach, 2nd ed. CRC Press. 
Haderlein, S.B., Weissmahr, K.W., Schwarzenbach, R.P., 1996. Specific adsorption of nitroaromatic explosives and pesticides to clay minerals. Environ. Sci. Technol. 30, 612-622.

Hawari, J., Monteil-Rivera, F., Perreault, N.N., Halasz, A., Paquet, L., Radovic-Hrapovic, Z., Deschamps, S., Thiboutot, S., Ampleman, G., 2015. Environmental fate of 2,4-dinitroanisole (DNAN) and its reduced products. Chemosphere 119, 16-23.

Jurgensen, H., 2000. DoD Moving Toward Long-Term Goal of IM-Compliant Inventory. PM, 3234.

Liang, J., Olivares, C., Field, J.A., Sierra-Alvarez, R., 2013. Microbial toxicity of the insensitive munitions compound, 2,4-dinitroanisole (DNAN), and its aromatic amine metabolites. J. Hazard. Mater. 262, 281-287.

Linker, B.R., Khatiwada, R., Perdrial, N., Abrell, L., Sierra, R., Field, J.A., Chorover, J., 2015. Adsorption of novel insensitive munitions compounds at clay mineral and metal oxide surfaces. Environmental Chemistry 12, 74-84.

Lotrario, J.B., Stuart, B.J., Lam, T., Arands, R.R., O'Connor, O.A., Kosson, D.S., 1995. Effects of Sterilization Methods on the Physical Characteristics of Soil: Implications for Sorption Isotherm Analyses. Bull. Environ. Contam. Toxicol. 54, 668--675.

Mark, N., Arthur, J., Dontsova, K., Brusseau, M., Taylor, S., 2016. Adsorption and attenuation behavior of 3-nitro-1,2,4-triazol-5-one (NTO) in eleven soils. Chemosphere 144, 1249-1255.

McDonald, L.M., Jr., Evangelou, V.P., 1997. Optimal solid-to-solution ratios for organic chemical sorption experiments. Soil Sci. Soc. Am. J. 61, 1655-1659. 
Olivares, C., Liang, J., Abrell, L., Sierra-Alvarez, R., Field, J.A., 2013. Pathways of reductive 2,4dinitroanisole (DNAN) biotransformation in sludge. Biotechnology and Bioengineering 110, $1595-1604$.

Olivares, C.I., Abrell, L., Khatiwada, R., Chorover, J., Sierra-Alvarez, R., Field, J.A., 2016. (Bio)transformation of 2,4-dinitroanisole (DNAN) in soils. J. Hazard. Mater. 304, 214-221.

Pang, L., Goltz, M., Close, M., 2003. Application of the method of temporal moments to interpret solute transport with sorption and degradation. J. Contam. Hydrol. 60, 123-134.

Perreault, N.N., Manno, D., Halasz, A., Thiboutot, S., Ampleman, G., Hawari, J., 2011. Aerobic biotransformation of 2,4-dinitroanisole in soil and soil Bacillus sp. Biodegradation.

Platten, W.E., Bailey, D., Suidan, M.T., Maloney, S.W., 2010. Biological transformation pathways of 2,4-dinitro anisole and N-methyl paranitro aniline in anaerobic fluidized-bed bioreactors. Chemosphere 81, 1131-1136.

Ro, K.S., Venugopal, A., Adrian, D.D., Constant, D., Qaisi, K., Valsaraj, K.T., Thibodeaux, L.J., Roy, D., 1996. Solubility of 2,4,6-Trinitrotoluene (TNT) in Water. Journal of Chemical \& Engineering Data 41, 758-761.

Roy, W.R., Krapac, I.G., Chou, S.F.J., Griffin, R.A., 1992. Batch-Type Procedures for Estimating Soil Adsorption of Chemicals. Risk Reduction Engineering Laboratory, Cincinnati, OH, p. 100 pp.

Saad, R., Radovic-Hrapovic, Z., Ahvazi, B., Thiboutot, S., Ampleman, G., Hawari, J., 2012. Sorption of 2,4-dinitroanisole (DNAN) on lignin. J. Environmental Sciences 24, 808-813. 
Salter-Blanc, A.J., Bylaska, E.J., Johnston, H.J., Tratnyek, P.G., 2015. Predicting Reduction Rates of Energetic Nitroaromatic Compounds Using Calculated One-Electron Reduction Potentials. Environ. Sci. Technol. 49, 3778-3786.

Shukla, M.K., Poda, A., 2016. Adsorption of Emerging Munitions Contaminants on Cellulose Surface: A Combined Theoretical and Experimental Investigation. Bull. Environ. Contam. Toxicol. 96, 784-790.

Šimůnek, J., van Genuchten, M.T., Šejna, M., 2008. Development and applications of the HYDRUS and STANMOD software packages, and related codes. Vadose Zone J. 7, 587-600.

Site, A.D., 2001. Factors Affecting Sorption of Organic Compounds in Natural Sorbent/Water Systems and Sorption Coefficients for Selected Pollutants. A Review.Journal of Physical and Chemical Reference Data 30, 187-439.

Stanley, J.K., Lotufo, G.R., Biedenbach, J.M., Chappell, P., Gust, K.A., 2015. Toxicity of the conventional energetics TNT and RDX relative to new insensitive munitions constituents DNAN and NTO in Rana pipiens tadpoles. Environ. Toxicol. Chem. 34, 873-879.

Taylor, S., Park, E., Bullion, K., Dontsova, K., 2015. Dissolution of three insensitive munitions formulations. Chemosphere 119, 342-348.

Taylor, S., Ringelberg, D.B., Dontsova, K., Daghlian, C.P., Walsh, M.E., Walsh, M.R., 2013. Insights into the dissolution and the three-dimensional structure of insensitive munitions formulations. Chemosphere 93, 1782-1788. 
Thorn, K.A., Kennedy, K.R., 2002. 15N NMR Investigation of the covalent binding of reduced TNT amines to soil humic acid, model compounds, and lignocellulose. Environ. Sci. Technol. 36, 3787-3796.

Thorn, K.A., Pennington, J.C., Hayes, C.A., 2002. ${ }^{15}$ N NMR investigation of the reduction and binding of TNT in an aerobic bench scale reactor simulating windrow composting. Environ. Sci. Technol. 36, 3797-3805.

Thorn, K.A., Pennington, J.C., Kennedy, K.R., Cox, L.G., Hayes, C.A., Porter, B.E., 2008. N-15 NMR study of the immobilization of 2,4- and 2,6-dinitrotoluene in aerobic compost. Environ. Sci. Technol. 42, 2542-2550.

U. S. Environmental Protection Agency, 1986. SW846 Method 9081. Cation-Exchange Capacity of Soils (Sodium Acetate). Office of Solid Waste and Emergency Response, Washington, DC.

U. S. Environmental Protection Agency, 1994. SW846 Method 8330. Nitroaromatics and Nitramines by HPLC. Office of Solid Waste and Emergency Response, Washington, DC.

U.S. Environmental Protection Agency, 2010. Standard Operating Procedure for Analysis of Total Organic Carbon in Sediments (Dry Combustion, IR Detection), Revision 04. Sampling and Analytical Procedures for GLNPO's Open Lake Water Quality Survey of the Great Lakes, EPA 905-R-05-001.

US Department of Health and Human Services, 1995. Toxilogical profile for 2,4,6-trinitrotoluene. Sciences International, Inc., pp. 87-113. 
Walsh, M.R., Walsh, M.E., Ramsey, C.A., Brochu, S., Thiboutot, S., Ampleman, G., 2013. Perchlorate contamination from the detonation of insensitive high-explosive rounds. J. Hazard. Mater. 262, 228-233.

Xie, R.J., Mackenzie, A.F., 1991. Effects of autoclaving on surface properties and sorption of phosphate and zinc in phosphate-treated soils. Soil Sci. 152, 250-258.

Zhang, D., Zhu D, W:, C., 2009. Sorption of nitroaromatics to soils: comparison of the importance of soil organic matter versus clay. Environ. Toxicol. Chem. 28, 1447-1454. 
Batch soil adsorption and column transport studies of 2, 4-

$$
\text { dinitroanisole (DNAN) }
$$

Supplementary Materials 
Table s1. Soil to solution ratio used in DNAN equilibrium tests.

\begin{tabular}{lcccc}
\hline Soil & $\begin{array}{c}\text { Soil:solution } \\
\text { ratio }\end{array}$ & Soil weight & $\begin{array}{c}\text { Volume of } \\
\text { Solution }\end{array}$ & $\begin{array}{c}\text { DNAN } \\
\text { adsorbed }\end{array}$ \\
\hline Catlin & $\mathrm{g} \mathrm{mL}^{-1}$ & $\mathrm{~g}$ & $\mathrm{~mL}$ & $\%$ \\
Fort Harrison & $1: 60$ & 0.33 & 20 & $50.6 \pm 2.8$ \\
Arnold AFB & $1: 60$ & 0.33 & 20 & $23.2 \pm 3.1$ \\
Plymouth & $1: 60$ & 0.33 & 20 & $21.3 \pm 2.6$ \\
Camp Butner & $1: 10$ & 2 & 20 & $24.7 \pm 0.9$ \\
Limestone Hills & $1: 60$ & 0.33 & 20 & $15.2 \pm 0.3$ \\
Sassafras & $1: 40$ & 0.5 & 20 & $20.9 \pm 1.2$ \\
Camp Gruber & $1: 60$ & 0.33 & 20 & $17.7 \pm 2.7$ \\
Camp Guernsey & $1: 40$ & 0.5 & 20 & $15.0 \pm 1.2$ \\
Florence & $1: 4$ & 5 & 20 & $26.8 \pm 3.2$ \\
Camp Swift & $1: 20$ & 1 & 20 & $17.8 \pm 0.1$ \\
& $1: 20$ & 1 & 20 & $13.4 \pm 1.4$ \\
\hline
\end{tabular}

Table s2. Catlin and Sassafras percent recoveries and 95\% confidence intervals (CI).

\begin{tabular}{|c|c|c|c|c|c|c|c|c|}
\hline Soil & Treatment & Time & $\begin{array}{l}\text { Solution } \\
\text { recovery }\end{array}$ & $95 \% \mathrm{CI}$ & $\begin{array}{c}\text { Soil } \\
\text { recovery }\end{array}$ & $\begin{array}{r}95 \% \\
\mathrm{CI} \\
\end{array}$ & $\begin{array}{c}\text { Total } \\
\text { recovery }\end{array}$ & $95 \% \mathrm{CI}$ \\
\hline & & $\mathrm{h}$ & --------. & ---- & $\%$ & ------' & ------ & ----- \\
\hline Catlin & unsterilized & 24 & 57.9 & 0.4 & 38.6 & 1.9 & 96.4 & 1.7 \\
\hline Catlin & unsterilized & 120 & 47.4 & 1.1 & 30.9 & 14.2 & 78.2 & 14.9 \\
\hline Catlin & sterilized & 24 & 76.9 & 1.8 & 23.8 & 2.6 & 100.7 & 4.4 \\
\hline Catlin & sterilized & 120 & 65.1 & 2.3 & 22.8 & 1.8 & 87.9 & 4.5 \\
\hline Sassafras & unsterilized & 24 & 87.5 & 0.5 & 11.9 & 3.0 & 99.3 & 3.0 \\
\hline Sassafras & unsterilized & 120 & 67.7 & 1.5 & 5.2 & 4.9 & 72.9 & 6.2 \\
\hline Sassafras & sterilized & 24 & 94.9 & 1.9 & 1.2 & 0.6 & 95.8 & 1.8 \\
\hline Sassafras & sterilized & 120 & 91.5 & 1.3 & 1.9 & 2.2 & 93.7 & 2.7 \\
\hline
\end{tabular}




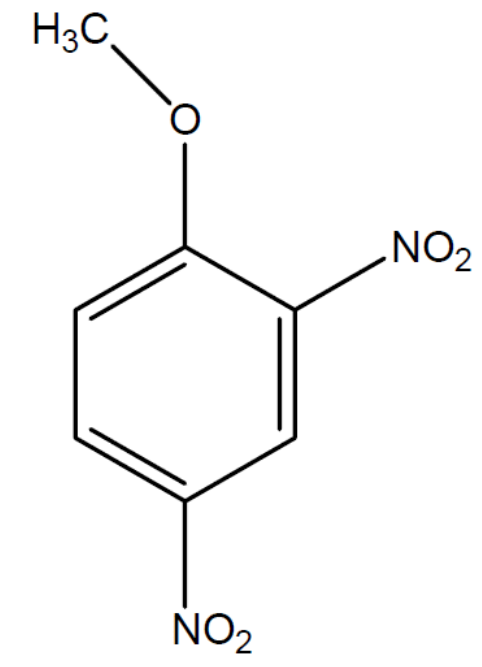

2,4-dinitroanisole DNAN

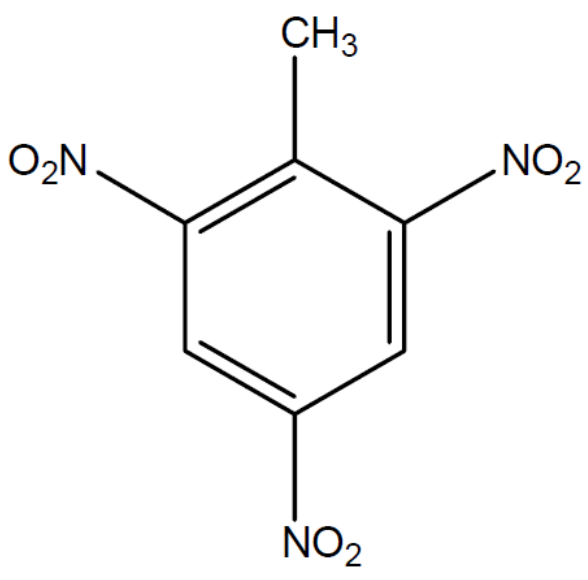

2,4,6-trinitrotoluene TNT

Figure s1. Structure of 2,4-dinitroanisole and 2,4,6-trinitrotoluene (Davies and Provatas, 2006). 

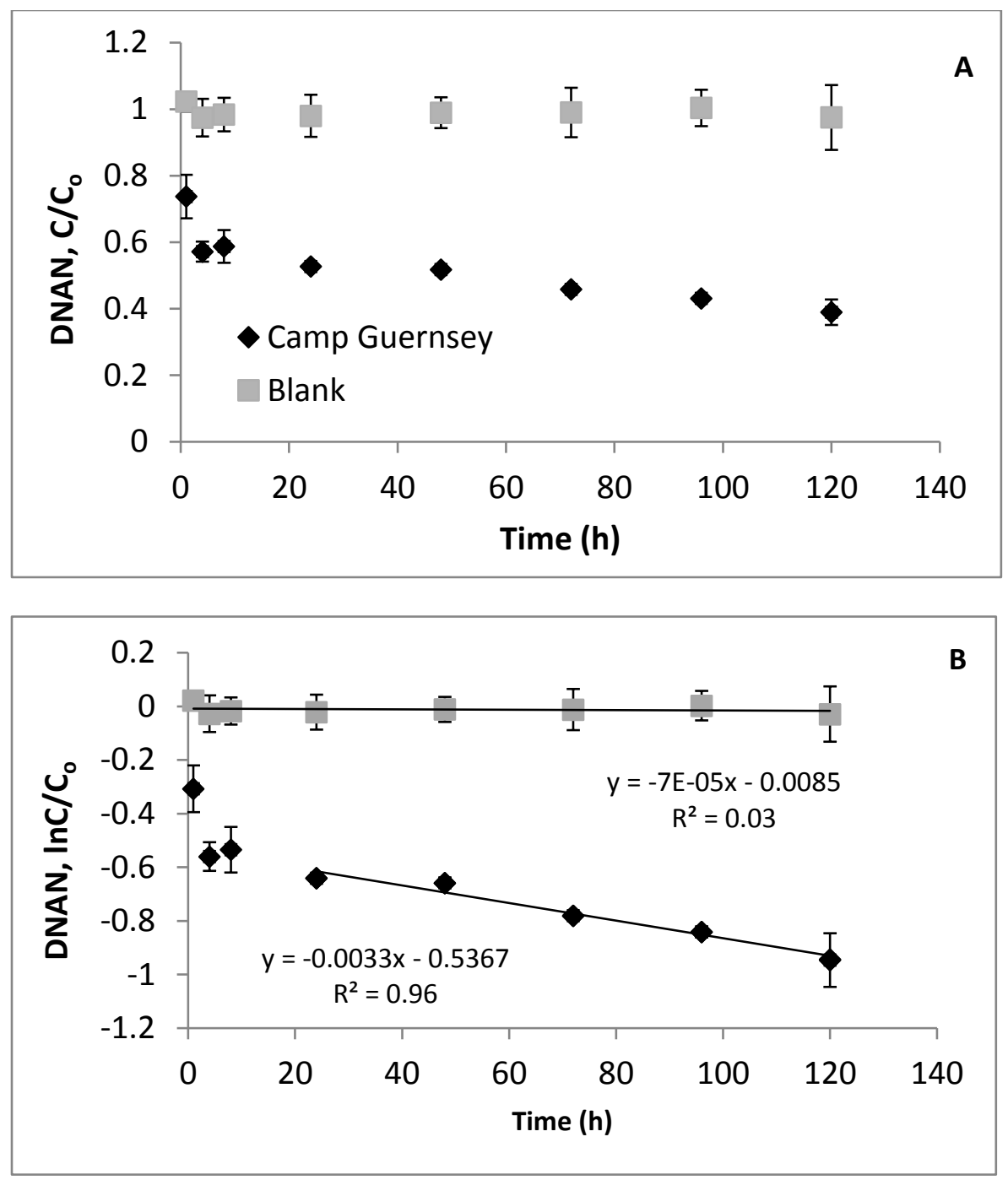

Figure s2. Plot of normalized DNAN solution concentration in contact with Camp Guerensey soil (A) and the same concentrations plotted as the natural logarithm (B), whose slope gives the mass-loss coefficient for DNAN, $k$. 

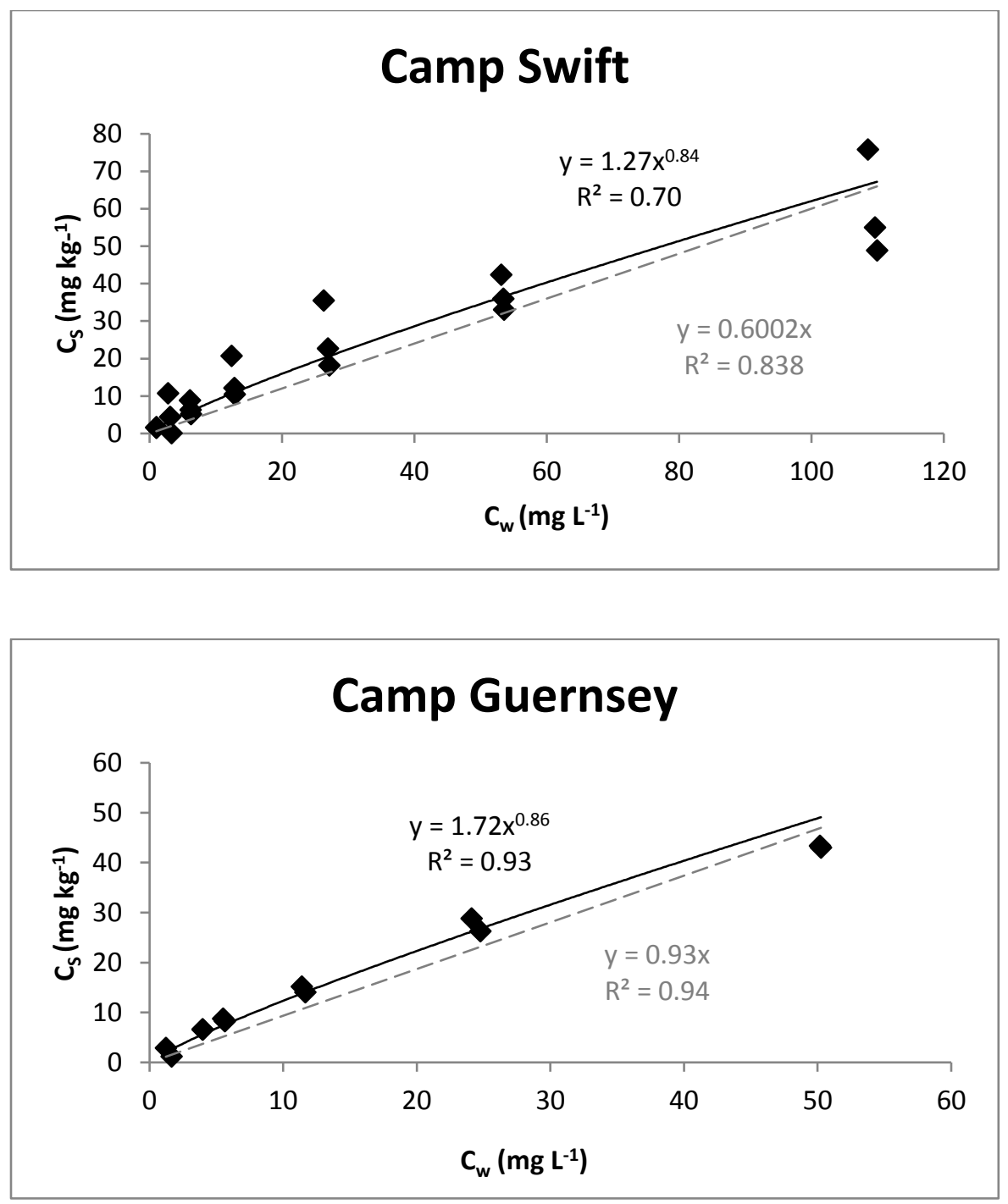

Figure s3. Adsorption isotherms calculated for DNAN in Camp Swift and Camp Guernsey soils. Grey dashed line indicates linear adsorption isotherm fit to the measured adsorption data (equation is in grey), while solid black line is a fit of the Freundlich isotherm (equation in black). 


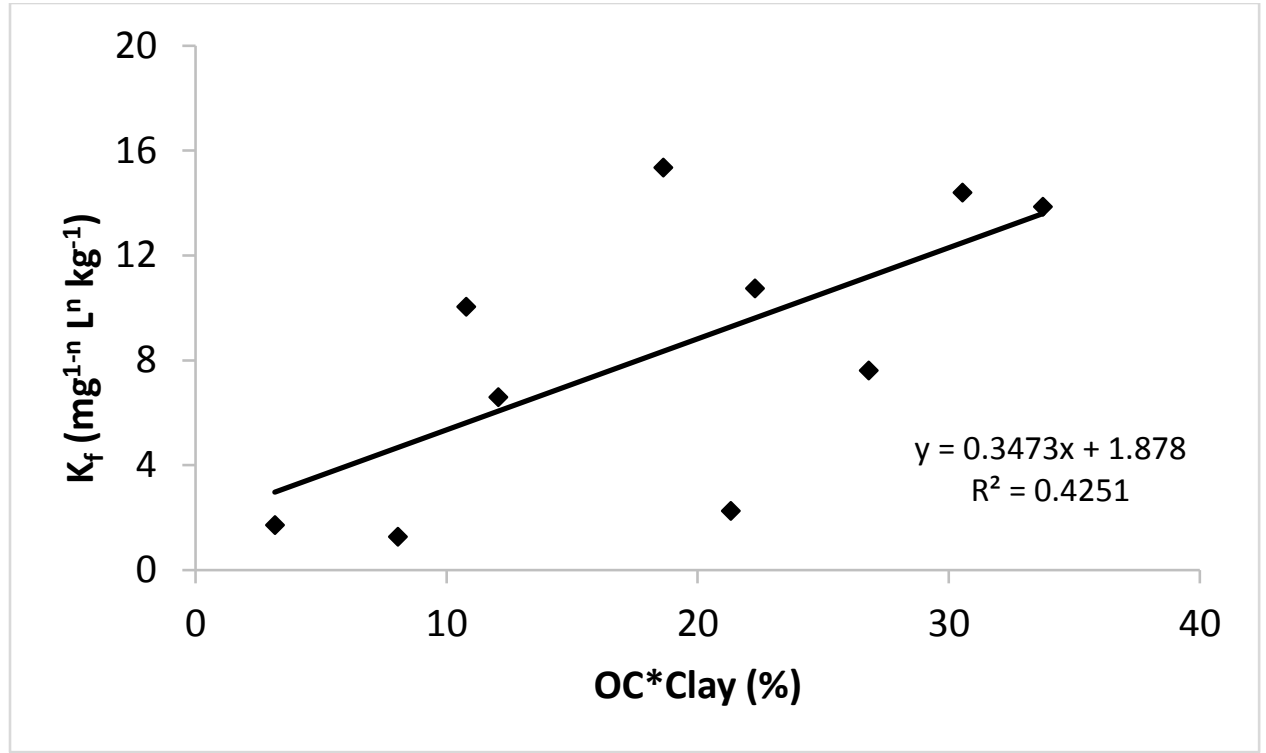

Figure s4. Correlation between measured DNAN Freundlich $\left(K_{f}\right)$ adsorption coefficient and the interaction of \% OC and \% clay $(\mathrm{P}=0.0410)$. The Thompson tau method was used to remove one outlier (Catlin soil) from the data set. 